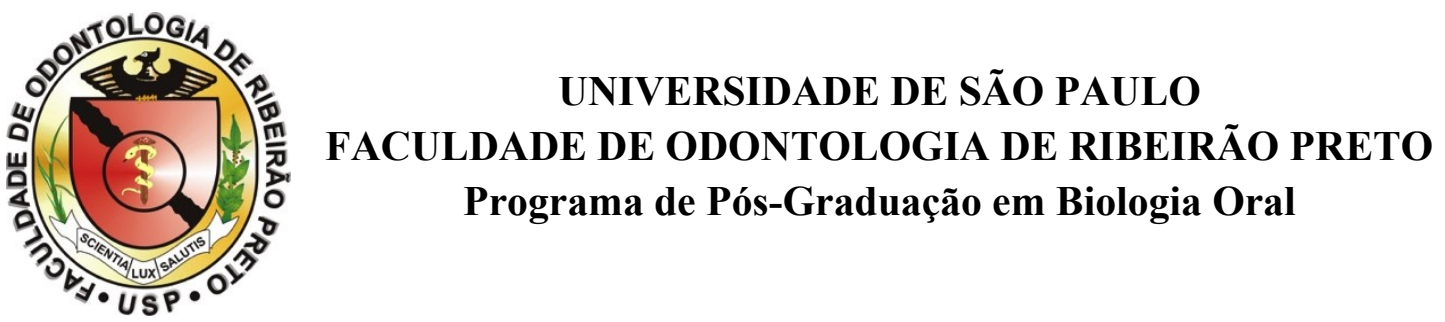

\title{
Avaliação dos efeitos do probiótico Bifidobacterium animalis subsp. lactis HN019 como terapia adjuvante no tratamento da periodontite experimental em ratos
}

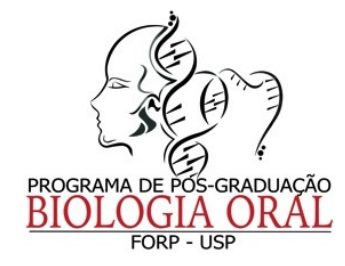

RIBEIRÃO PRETO 


\section{Avaliação dos efeitos do probiótico Bifidobacterium animalis subsp. lactis HN019 como terapia adjuvante no tratamento da periodontite experimental em ratos}

Dissertação apresentada à Faculdade de Odontologia de Ribeirão Preto da Universidade de São Paulo, para a obtenção do título de Mestre em Ciências.

Área de concentração: Biologia Oral

Orientador: Prof. Dr. Michel Reis Messora 
Autorizo a reprodução e divulgação total ou parcial deste trabalho, por qualquer meio convencional ou eletrônico, para fins de estudo e pesquisa, desde que citada a fonte.

\section{Catalogação da Publicação}

Biblioteca Central do Campus USP - Ribeirão Preto

Faculdade de Odontologia de Ribeirão Preto da Universidade de São Paulo

Ricoldi, Milla Sprone Tavares,

Avaliação dos efeitos do probiótico Bifidobacterium animalis subsp. lactis HN019 como terapia adjuvante no tratamento da periodontite experimental em ratos. Ribeirão Preto, 2017. 113 p. : il. ; $30 \mathrm{~cm}$

Dissertação de Mestrado, apresentada à Faculdade de Odontologia de Ribeirão Preto/USP. Área de concentração: Biologia Oral.

Orientador: Prof. Dr. Michel Reis Messora

1. Doença Periodontal. 2. Probióticos. 3. Ratos. 4. Bifidobacterium. 5. Raspagem Dentária. 


\section{FOLHA DE APROVAÇÃO}

RICOLDI, M. S. T. Avaliação dos efeitos do probiótico Bifidobacterium animalis subsp. lactis HN019 como terapia adjuvante no tratamento da periodontite experimental em ratos. 2017. 113f. Dissertação (Mestrado) - Faculdade de Odontologia de Ribeirão Preto, Universidade de São Paulo, Ribeirão Preto, 2017.

Dissertação apresentada à Faculdade de Odontologia de Ribeirão Preto da Universidade de São Paulo, para obtenção do título de Mestre em Ciências.

Área de concentração: Biologia Oral.

Aprovado em:

Banca Examinadora

Prof(a). Dr(a).:

Instituição:

Julgamento:

Assinatura:

Prof(a). Dr(a).:

Instituição:

Julgamento: Assinatura:

$\operatorname{Prof(a).~} \operatorname{Dr}(a)$ :

Instituição:

Julgamento: Assinatura:

Prof(a). Dr(a).:

Instituição:

Julgamento: Assinatura: 
Dedicatóría 


\section{A Deus,}

obrigado senhor por íluminar minha vida e Nossa senhora por interceder em cada obstáculo. Peço que continuem me acompanhando, abençoando $e$ iluminando cada momento. Alivie cada dor que en precisar passar, pois sem a influência do senhor na minha vida não consigo continuar. Meu eterno $e$ infinito agradecimento SENHOR. 


\section{A meu marido Thíago Rícoldi,}

Meu agradecimento e meu respeito por toda dedicação e companheirismo. você me faz uma pessoa muito feliz e realizada. Que Deus continue abençoando nosso casamento. Te amo! 


\section{Aos meus pais Matheus (in memorian) e}

\section{Rosana,}

Nessa momento só me vem a cabeça a seguinte música:

"Eu tenho tanto pra lhe falar

Mas com palavras não sei dizer

comoé grande o meu amor por você

Enão ha nada pra comparar

para poder the explicar

comoé grande o meu amor por vocêe

Nem mesmo o céu, nem as estrelas

Nem mesmo o mar e o infinito

Não é maior que o meu amor, nem mais bonito

Me desespero a procurar

Alguma forma de lhe falar

comoé grande o meu amor por vocêe

Nunca se esqueça nem um segundo

Que eu tenho o amor maíor do mundo

como é grande o meu amor por você

Mas como é grande o meu amor por você"

Amovocês! 


\section{A meuirmão caío,}

o bom de ser irmã mais velha é testar com seu irmão mais novo o dom de ser mãe sem compromisso. vocêé o meu irmão muito amado e agradeço a Deus por ter colocado você para compartílhar os momentos da minha vida. Te amo de qualquer jéito. 
Aos meus avós vaíne (in memorian) e Laura,

Sou um pouquinho de vocês e agradeço por todas as conversas, brincadeiras e comidinhas que dividimos juntos. Amo vocês.

\section{Aos meus avós Mariana (in memorian) evaldevino,}

Sou mais um pouquinho de vocês e agradeço por todas as brincadeiras, conversas e controversas, só serviram para moldar a pessoa que sou hoje. Amo vocês. 
Agradecimento especial 


\section{A meu orientador Prof. Dr. Michel Reis Messora,}

Quero agradecer por aceitar ser meu orientador e deixar muitos trabalhos sob minha responsabilidade no laboratório, isso serviu para aprimorar meus conhecimentos profissionais. com essas portas abertas consigo enriquecer men currículo e quem sabe algum día também ser uma professora. O senhor é um grande amigo de seus alunos. Sou eternamente grata. Muito obrigado! 
Agradecimentos 
A caminhada foi longa e dura, se hoje estou aqui, foi porque me apoiei em ombros fortes. Dessa forma, agradeço:

Aos professores do departamento de cirurgía e Traumatologia Buco-Maxilo-Facial e Periodontia, que incentivam os técnicos deste departamento aprimorar o currículo profissional.

A professora Dra. Daniela Palioto pelas palavras de incentivo e por facilitar o mecanismo laboratorial tornando possivel a execução dos ensaios. Tentaréi colocar em prática cada conselho que recebi da senhora.

Aos professores Dr. Mário Taba Junior e Dr. Sérgio Luis scombatti de souza, meu profundo carinho, pois foram os primeiros professores que tive contato quando entrei na FORP-USP e me receberam muitissimo bem.

Ao professor Dr. Arthur Belém Novaes Júnior, que sempre esteve pronto a me ouvir nos momentos de necessidade e me auxilion na execução das melhorias laboratoriais. obrigado! 
Ao professor Dr. Adalberto Luíz Rosa, minha profunda admiração e gratidão, uma vez que me ajudou a enxergar a dose certa do convivio profissional. Muitissimo obrigado!

Aos professores Dr. Paulo Tambasco de Oliveira e Dra. Karina Fittípaldi Bombonato Prado, agradeço pela oportunidade do convivio e exemplos de profissionais de profunda humanidade.

Ao professor Dr. Márcio Mateus Beloti, meu respeito pela paciêncía que teve com cada aluno do novo Programa de Biología oral. Muito obrigado.

Ao professor Dr. Sérgío salvador, obrigado pela atenção para realização da análise microbiológica. 
A todos os amigos, profissionais e familiares que, de alguma forma, me incentivaram nas etapas indispensaveis deste projeto, registro aqui meus agradecimentos:

Aos meus amigos pós-graduandos Rodrigo Paolo flores Abuna e Luiz Fernando Ferreira de oliveira que me acompanharam ao longo dessa trajetória, muito obrigado. com a ajuda de vocês ficon mais facil a caminhada.

As alunas de iniciação científica cisele Aparecida da silva, Giovana conçalves Martins e Laura cacheta waldemarin, obrigado pela dedicação na execução das etapas que cada uma ficou responsavel de ajudar. Nossas risadas foram muito importantes para ultrapassar as dificuldades.

A técnica Marina Del Arco agradeço a ajuda com o preparo e cultivo do probítíco no laboratório e Microbiología da Faculdade de Farmácía de Ribeirão Preto. 
A todos os meus amigos e amigas alunos que em algum momento me ajudaram durantes as aulas, os ensaios laboratoriais, durante a documentação, nas ideias, sugestões, dividindo experiencías e palavras de carinho meu muito obrigado e meu profundo carinho por todos. como são muitos citaréi nomes, porém quero déixar registrado que desde 2010 (ano que fui contratada) cada aluno que pude conviver me fez uma pessoa melhor. obrigado galera!

A mens queridos professores laboratoriais fabiola Singaretti de Oliveira e Roger Rodrigo Fernandes, por dividirem os conhecimentos profissionais comigo. Terão sempre meu respeito e admiração.

A mens companheiros de trabalho Adriana Luisa Gonçalves de Almeida, sebastião carlos Bianco, Aparecida Dulce de OLiveira Negretí, Carla Daniela Lima da Silva e Tatiana Angeli Passos Fernandes muito obrigado pelo carinho e orientações para construção da minha carreira.

A todos os funcionarios da FORP pelo carinho $e$ disponibuilidade. 
A Faculdade de odontología de Ríbeirão Preto (FORP) da universidade de São Paulo e à Fundação de Amparo à Pesquisa do Estado de São Paulo - FAPESP, pelo apoío financeiro para a realização deste estudo. 


\section{Epigrafe}

"Posso, tudo posso Naquele que me fortalece,

Nada e ninguém no mundo vai me fazer desistir, Quero, tudo quero, sem medo entregar meus projetos, Déxar-me guiar nos caminhos que Deus desejou pra mim e ali estar" - compositora celina Borges 
Resumo 


\section{Resumo}

RICOLDI, M. S. T. Avaliação dos efeitos do probiótico Bifidobacterium animalis subsp. lactis HN019 como terapia adjuvante no tratamento da periodontite experimental em ratos. 2017. 113f. Dissertação (Mestrado) - Faculdade de Odontologia de Ribeirão Preto, Universidade São Paulo.

Probióticos do gênero Lactobacillus estão sendo amplamente investigados no tratamento da periodontite. Contudo, os efeitos de microrganismos do gênero Bifidobacterium ainda são pouco conhecidos. Este estudo avaliou os efeitos do probiótico Bifidobacterium animalis subsp. lactis (B. lactis) HN019 como adjuvante à raspagem e alisamento radicular (RAR) no tratamento da periodontite experimental (PE) em ratos. No dia 0 do experimento, 32 ratos foram alocados em 4 grupos: $\mathrm{C}$ (controle), PROB (probiótico), PE-RAR e PE-RARPROB. Nos grupos PE-RAR e PE-RAR-PROB, a PE foi induzida pela colocação de ligaduras de seda ao redor dos primeiros molares inferiores dos animais. No $14^{\circ}$ dia, as ligaduras foram removidas e realizou-se a RAR. Nos animais dos grupos PROB e PE-RARPROB, o probiótico B. lactis HN019 foi administrado diariamente $\left(10 \mathrm{~mL} / \mathrm{dia}\right.$ de $10^{9}$ unidades formadoras de colônia) por 15 dias tendo seu início no $14^{\circ}$ dia do experimento. Os animais de todos os grupos foram submetidos à eutanásia 29 dias após o início do experimento. As hemimandíbulas e amostras de intestino delgado foram coletadas. Foram realizadas análises histomorfométricas, microtomográficas e imunohistoquímicas. Foram investigados, também, os efeitos microbiológicos de B. lactis HN019 no biofilme associado às ligaduras durante o desenvolvimento da PE. Todos os dados foram analisados estatisticamente. O Grupo PE-RAR-PROB apresentou menores reabsorção óssea alveolar e perda de inserção conjuntiva quando comparado ao Grupo PE-RAR, bem como menor número de osteoclastos, maior expressão de citocinas anti-inflamatórias e menor expressão de citocinas pró-inflamatórias ( $p<0,05$ ). No grupo PE-RAR-PROB, os valores médios da profundidade da cripta do jejuno e duodeno foram significativamente maiores que aqueles do grupo PE-RAR. A proporção de bactérias aeróbias/anaeróbias foi maior nas amostras de biofilme de animais tratados com B. lactis HN019 em relação àquelas de animais não tratados $(p<0,05)$. Dentro dos limites deste estudo, pode-se concluir que a utilização de $B$. lactis HN019 como adjuvante à RAR promove benefícios histológicos, microtomográficos e imunológicos adicionais no tratamento da PE em ratos, bem como melhora a morfologia intestinal.

Palavras-chave: Doença Periodontal; Probióticos; Ratos; Bifidobacterium; Raspagem Dentária. 
Abstract 


\begin{abstract}
Ricoldi, M. S. T. Effects of the probiotic Bifidobacterium animalis subsp. lactis HN019 as an adjunct to treatment of experimental periodontitis in rats. 2017. 113f. Dissertation (Master's Degree) - School of Dentistry of Ribeirão Preto, University of São Paulo.
\end{abstract}

Lactobacillus probiotics have been investigated in periodontitis. However, the effects of the genus Bifidobacterium on periodontitis are hardly known. This study evaluated the effects of the probiotic Bifidobacterium animalis subsp. lactis (B. lactis) HN019 as an adjunct to scaling and root planing (SRP) in rats with experimental periodontitis (EP). At baseline, 32 rats were assigned to 4 groups: $\mathrm{C}$ (control), PROB, EP-SRP and EPSRP-PROB. In groups EP-SRP and EP-SRP-PROB, the mandibular first molars of the animals received a ligature. At day 14, the ligatures were removed and SRP was performed. Animals of groups PROB and EP-SRP-PROB were orally administered with $10 \mathrm{~mL} /$ day of $10^{9}$ colony forming units of B. lactis HN019 for 15 days, starting at day 14. Animals were euthanized at day 29. The jaws and samples of the duodenum, jejunum, and ileum were resected. Histomorphometric, microtomographic and immunohistochemical analyses were performed. Microbiological effects of B. lactis on biofilm were also evaluated. Data were statistically analyzed. Group EP-SRP-PROB presented reduced alveolar bone resorption and attachment loss when compared with Group EP-SRP $(p<0.05)$. Group EP-SRP-PROB showed significantly fewer osteoclasts, increased expression of anti-inflammatory cytokines and reduced expression of proinflammatory cytokines compared with Group EP-SRP $(p<0.05)$. In group EP-SRPPROB, the mean values of crypt depth of the jejunum and dudoenum were significantly higher than the ones from group EP-SRP. B. lactis promoted a higher ratio between aerobic and anaerobic bacteria in biofilm samples $(p<0.05)$. Within the limits of this study it can be concluded that the use of B. lactis HN019 as an adjunct to SRP promotes additional histologic, microtomographic and immunologic benefits in the treatment of EP in rats and improves the intestinal morphology.

Keywords: Periodontal Diseases; Probiotics; Rats, Bifidobacterium; Dental Scaling. 


\section{Lista de figuras}




\section{LISTA DE FIGURAS}

Figura 1 - (A) Animal posicionado para a colocação da ligadura; (B) 49 Fio de seda em posição para indução da doença periodontal no $1^{\circ}$ molar inferior.

Figura 2 - $\quad$ Medidas lineares (linhas vermelhas) das distâncias ( $\boldsymbol{\mu m}$ ) 51 entre a junção cemento-esmalte e a crista óssea alveolar realizadas nos cortes microtomográficos visualizados no eixo transaxial (A - vestibular; B - lingual; C interproximal) e no eixo sagital (D - bifurcação).

Figura 3 - $\quad$ Medidas volumétricas realizadas na região de bifurcação do $1^{0}$ molar inferior em cortes microtomográficos visualizados no eixo coronal. (A) A região de interesse a ser analisada (ROI) foi delimitada por um retângulo que tangenciava as quatro raízes do $1^{\circ}$ molar inferior. (B) As imagens foram binarizadas para separação das estruturas óssea e dentária (por diferença de densidade), utilizando uma escala de níveis de cinza (grayscale threshold 0-255).

Figura 4 - $\quad$ Análise Histomorfométrica - imagem ilustrativa dos tecidos periodontais da região de bifurcação (A) e da região interproximal (B) entre o $1^{\circ}$ e $2^{\circ}$ molares inferiores de animais com doença periodontal. A linha vermelha representa a medida linear $(\mathrm{mm})$ do nível de inserção conjuntiva na região interproximal. A linha azul delimita a área sem osso alveolar na região de bifurcação. Coloração: Hematoxilina e Eosina. Aumento original $=10 \mathrm{x}$. JCE $=$ junção cemento-esmalte; $\mathrm{OA}=$ osso alveolar; $\mathrm{IC}=$ inserção conjuntiva; $\mathrm{PMI}=$ primeiro molar inferior; $\mathrm{SMI}=$ segundo molar inferior.

Figura 5 - $\quad$ Análise histomorfométrica dos tecidos periodontais. Médias e desvios padrão de ASOA (A, área de bifurcação) e NIC (B, área interproximal), com comparações entre grupos. Fotomicrografias dos tecidos periodontais na região de bifurcação (C-F) e áreas interproximais (G-J) dos $1^{\text {os }}$ molares inferiores: Grupo C (C e G); Grupo PROB (D e H); Grupo PE-RAR (E e I); Grupo PE-RAR-PROB (F e J). Abreviaturas e símbolos: oa $=$ osso alveolar; tc $=$ tecido conjuntivo; $1 \mathrm{p}=$ ligamento periodontal; $\mathrm{ASOA}=$ área sem osso alveolar; NIC = nível de inserção conjuntiva; PMI = primeiro molar inferior; $\mathrm{SMI}=$ segundo molar inferior; Setas pretas $=$ junção cemento-esmalte; Setas brancas $=$ inserção epitelial; $*=p<0,05 ; * *=p<0,01 ; * * *=p<0,001$. Barras de escala: C-J $=200 \mu \mathrm{m}$. (Hematoxilina e Eosina). 
Figura 6 - Análise imunohistoquímica - TRAP. Médias e desvios padrão do número de células multinucleadas positivas para TRAP (A), com comparações entre grupos. Fotomicrografias mostrando imunomarcação para TRAP (B-E) na região de bifurcação dos $1^{\text {os }}$ molares inferiores: Grupo C (B); Grupo PROB (C); Grupo PE-RAR (D); Grupo PE-RAR-PROB (E). Abreviaturas e símbolos: oa $=$ osso alveolar; $\mathrm{tc}=$ tecido conjuntivo; $1 \mathrm{p}=$ ligamento periodontal; Seta preta $=$ célula multinucleada TRAP-positiva; $*=p<0,05 ; * *=p<0,01$; $* * *=p<0,001$. Barras de escala: $\mathrm{B}-\mathrm{E}=20 \mu \mathrm{m}$. (Contracoloração com hematoxilina).

Figura 7 - Análise imunohistoquímica - IL-1 $\beta$ e CINC. Medianas, 63 intervalo interquartil e valores máximos e mínimos dos escores de imunomarcação para IL-1 $\beta$ (A) e CINC (B), com comparações entre os grupos. Fotomicrografias mostrando imunomarcação para IL-1 $\beta$ (C-F) e CINC (G-J) nas áreas de bifurcação dos $1^{\text {os }}$ molares inferiores: Grupo $C(C$ e $G)$; Grupo PROB (D e H); Grupo PE-RAR (E e I); Grupo PERAR-PROB ( $\mathrm{F}$ e J). Abreviaturas e símbolos: oa $=$ osso alveolar; tc $=$ tecido conjuntivo; $1 \mathrm{p}=$ ligamento periodontal; $*=p<0,05$. Barras de escala: C-J $=80 \mu \mathrm{m}$. (Contracoloração com hematoxilina).

Figura 8 - $\quad$ Análises imunohistoquímicas - IL-10 e TGF- $\beta 1$. Medianas, 64 intervalo interquartil e valores máximos e mínimos dos escores de imunomarcação para IL-10 (A) e TGF- $\beta 1$ (B), com comparações entre os grupos. Fotomicrografias mostrando imunomarcação para IL-10 (C-F) e TGF- $\beta 1$ (G-J) nas áreas de bifurcação dos $1^{\text {os }}$ molares inferiores: Grupo $\mathrm{C}$ (C e G); Grupo PROB (D e H); Grupo PE-RAR (E e I); Grupo PE-RAR-PROB (F e J). Abreviaturas: oa = osso alveolar; tc $=$ tecido conjuntivo; $1 \mathrm{p}=$ ligamento periodontal; $*=p<0,05$. Barras de escala: C-J $=80 \mu \mathrm{m}$. (Contracoloração com hematoxilina).

Figura 9 - Análise histomorfométrica do intestino delgado. Valores 66 médios e desvios padrão de AV (A) e PC (B) em seções intestinais, com comparações entre os grupos. Fotomicrografias do intestino delgado (seções do duodeno): Grupo C (C); Grupo PE-RAR (D); Grupo PROB (E); Grupo PE-RAR-PROB (F). Abreviaturas e símbolos: $\mathrm{CL}=$ cripta de Lieberkühn; $\mathrm{AV}=$ altura de vilosidades; $\mathrm{PC}=$ profundidade da criptas; Seta preta $=$ células calciformes; $*$ $=$ Diferença significativa $(p<0,05)$ quando comparado com 
os Grupos C, PE-RAR e PE-RAR-PROB; $\uparrow=$ Diferença significativa $(p<0,05)$ entre os grupos PE-RAR e PE-RARPROB; $+=$ Diferença significativa $(p<0,05)$ entre os grupos $\mathrm{C}$ e PE-RAR-PROB; $\S=$ Diferença significativa $(p<0,05)$ entre os grupos $\mathrm{C}$ e PE-RAR. Barras de escala: $\mathrm{C}-\mathrm{F}=50 \mu \mathrm{m}$. (Hematoxilina e Eosina).

Figura 10 - Efeitos de $B$. lactis HN019 na microbiota associada às ligaduras durante o desenvolvimento da periodontite experimental. Médias e desvios padrão da razão entre bactérias aeróbias e anaeróbias nos grupos Teste e Placebo. * $=$ Diferença significativa $(p<0,05)$ quando comparado ao Grupo Placebo. 


\section{Lista de tabela}




\section{LISTA DE TABELAS}

Tabela 1 - $\quad$ Análises com micro-CT. Médias e desvios padrão (DP) de VO 59 $(\%)$, PO $(\%)$ e NOA $(\mu \mathrm{m})$ dos grupos $\mathrm{C}$, PROB, PE-RAR e PERAR-PROB, com comparações entre os grupos. 


\section{Lista de abreviaturas e siglas}




\section{LISTA DE ABREVIATURAS E SIGLAS}

\section{B. lactis Bifidobacterium animalis subsp. Lactis}

CCI Coeficiente de correlação intraclasse

CEUA Comissão de ética no uso de animal

cm Centímetro

CO Crista óssea alveolar

DP Doença periodontal

PE Periodontite experimental

C Controle

PROB Probiótico

EDTA Ácido etilenodiaminio tetra-acético

EUA Estados Unidos da América

Ex Exemplo

FORP Faculdade de Odontologia de Ribeirão Preto

G Grama

H\&E Hematoxilina e Eosina

IL Interleucina

JCE Junção cemento esmalte

micro-CT Microtomografia computadorizada

mL Mililitro

NIC Nível de inserção conjuntiva

NOA Nível ósseo alveolar

PBS Tampão fosfato salino

PO Porosidade óssea

RAR Raspagem e alisamento radicular

UFC Unidades formadoras de colônias

UNESCO Organização das Nações Unidas para Educação, a Ciência e a 
Cultura.

USP Universidade de São Paulo

VO Volume ósseo

VOI Volume de interesse

$\mu \mathrm{m} \quad$ Micrometro

OA Osso alveolar

IC Inserção conjuntiva

PMI Primeiro molar inferior

SMI Segundo molar inferior

TRAP Fosfatase Ácida Tartarato Resistente

CINC Citocina quimioatraente para neutrófilos

TGF Fator de crescimento transformador

AV Altura de vilosidade

PC Profundidade de cripta

ASOA Área sem osso alveolar

BD Beta-defensina

OPG Osteoprotegerina

RANKL Ligante do receptor ativador do fator nuclear kappa beta 
Lista de símbolos 


\section{LISTA DE SÍMBOLOS}

$\begin{array}{ll}\text { \% } & \text { Porcentagem } \\ \boldsymbol{\beta} & \text { Beta } \\ \boldsymbol{\alpha} & \text { Alfa } \\ \boldsymbol{p} & \text { Probabilidade de significância } \\ < & \text { Menor } \\ > & \text { Maior } \\ \text { (B) } & \text { Marca registrada } \\ = & \text { Igual } \\ \pm & \text { Mais ou menos } \\ { }^{\circ} \mathbf{C} & \text { Graus Celsius } \\ \mathbf{n} & \text { Tamanho da amostra } \\ + & \text { Mais } \\ \mathbf{x} & \text { Vezes } \\ - & \text { Menos }\end{array}$




\section{Sumario}




\section{SUMÁRIO}

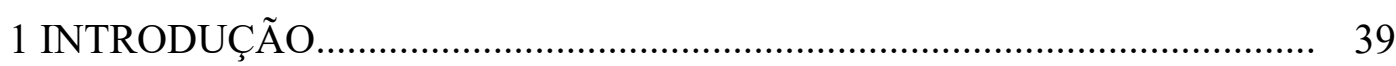

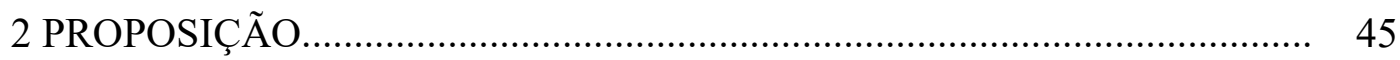

3 MATERIAIS E MÉTODOS............................................................... 47

3.1 Apreciação ética.................................................................................... 47

3.2 Cálculo do tamanho da amostra........................................................ 47

3.3 Modelo experimental...................................................................... 47

3.4 Indução da DP com ligadura.............................................................. 48

3.5 Raspagem e alisamento radicular - RAR ............................................ 48

3.6 Administração da terapia probiótica...................................................... 49

3.7 Eutanásia e coleta de material para análises......................................... 49

3.8 Microtomografia computadorizada por transmissão de raios X (micro-CT)

3.9 Análise histomorfométrica dos tecidos periodontais........................... 53

3.10 Análise imunohistoquímica dos tecidos periodontais....................... 54

3.11 Análise histomorfométrica do intestino delgado............................... 55

3.12 Efeitos de B. lactis HN019 na microbiota associada às ligaduras..... 55

3.13 Validação da RAR como tratamento da PE..................................... 55

3.14 Variáveis de resultado................................................................... 56

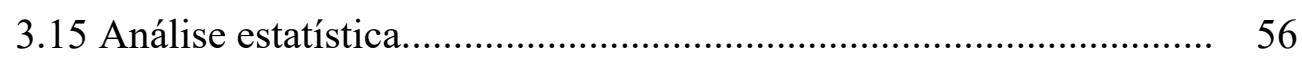

4 RESULTADOS

4.1 Análise com microtomografia computadorizada por transmissão de

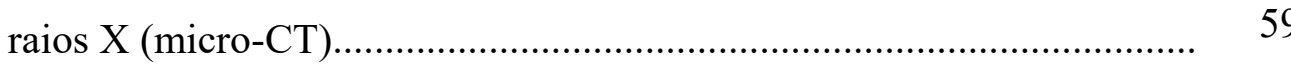

4.2 Análise histomorfométrica dos tecidos periodontais............................ 60

4.2.1 Análise histopatológica............................................................ 60 
4.2.2 Análise histométrica.......................................................... 60

4.3 Análise imunohistoquímica............................................................. 62

4.4 Análise histomorfométrica do intestino delgado............................... 65

4.4.1 Análise histopatológica....................................................... 65

4.4.2 Análise histométrica........................................................ 65

4.5 Efeitos de B. lactis HN019 na microbiota associada às ligaduras 67

4.6 Validação da RAR como tratamento da PE....................................... 67

5 DISCUSSÃO

6 CONCLUSÃO

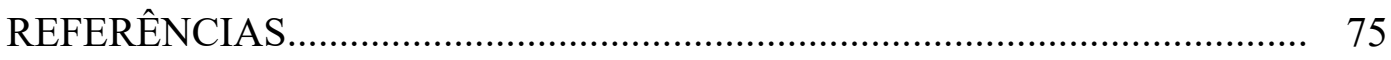

ANEXO 
introdução 
A doença periodontal (DP) é uma doença inflamatória crônica que afeta os tecidos de suporte dos dentes e pode levar à perda dentária, afetando grande parte da população. Em um levantamento epidemiológico realizado nos Estados Unidos da América, foi demonstrado que um em cada dois americanos com 30 anos de idade ou mais possui DP (1) Neste estudo, 47\% da amostra examinada, representando 64,7 milhões de adultos, apresentava periodontite nas formas leve $(8,7 \%)$, moderada $(30 \%)$ e severa (8,5\%). Para adultos com 65 anos de idade ou mais, o percentual de ocorrência de periodontite moderada ou severa foi de $64 \%$ (1).

O biofilme bacteriano é o fator etiológico primário para o início da inflamação gengival e subsequente destruição dos tecidos periodontais (2) Entretanto, a presença isolada do biofilme responde por uma pequena proporção $(20 \%)$ de variações na expressão da DP (3). De acordo com um novo modelo de patogênese, o principal componente de destruição de tecidos duros e moles na DP é resultado da ativação da resposta imunoinflamatória do hospedeiro às agressões bacterianas (4). Fatores de risco adquiridos e ambientais (ex.: diabetes, fumo e estresse), bem como algumas características geneticamente transmitidas (ex.: polimorfismos gênicos para a interleucina [IL]-1) podem acentuar a resposta inflamatória decorrente da agressão bacteriana e, eventualmente, a suscetibilidade à DP (4).

Raspagem e alisamento radicular (RAR) é a terapia de escolha pela maioria dos clínicos e amplamente considerada o "padrão-ouro" para o tratamento da periodontite (5). Contudo, o uso isolado da RAR não produz os resultados clínicos desejados em alguns casos severos de DP. Nestas situações, ocorre recolonização de patógenos e a recorrência da doença (5), o que remete o clínico ao uso da terapia antimicrobiana associada à RAR para um tratamento efetivo dos pacientes/sítios não responsivos ao tratamento convencional. Além disso, devido ao fato da resposta do hospedeiro também desempenhar um importante papel na progressão da doença, tratamentos supressores da inflamação, os chamados moduladores da resposta do hospedeiro, têm sido investigados (5). A possibilidade de modular a resposta do hospedeiro interferindo na expressão de citocinas pró-inflamatórias foi demonstrada em um estudo realizado por Assuma et al. (6). Neste estudo, a injeção local de antagonistas de algumas ILs pró-inflamatórias em dentes de primatas com periodontite induzida pela colocação de ligaduras infectadas com Porphyromonas gingivalis reduziu em $80 \%$ o recrutamento de células inflamatórias, em $67 \%$ a formação de osteoclastos e em $60 \%$ a perda óssea quando comparados com dentes controles que não receberam a injeção local dos antagonistas 
(6). Em síntese, o uso de quimioterapias adjuvantes no tratamento periodontal tem como objetivo tratar sítios que não respondem ao tratamento convencional ou potencializar resultados normalmente obtidos com a instrumentação mecânica, evitando, assim, a necessidade de procedimentos adicionais para a redução de bolsas periodontais (7).

Considerando as limitações da RAR no tratamento da DP (5), a recolonização de bolsas periodontais após realização da RAR (8) e a participação de vários mecanismos referentes ao sistema imune inato e adaptativo do hospedeiro na patogênese da doença, o uso de probióticos como uma nova terapia adjuvante para a periodontite tem despertado o interesse da comunidade científica odontológica, desde que os mesmos podem modular a resposta imunoinflamatória do hospedeiro e modificar o ambiente bacteriano.

A definição consensual de probióticos usada atualmente foi apresentada pela Organização Mundial de Saúde e pela Organização de Alimentação e Agricultura dos Estados Unidos da América. Essas organizações definiram probióticos como "microorganismos vivos que, quando administrados em quantidades adequadas, conferem um benefício para a saúde no hospedeiro" (ftp://ftp.fao.org/es/esn/food/wgreport2.pdf). Esta definição restringe a utilização da palavra probiótico a produtos que contêm microrganismos vivos e aponta a necessidade de proporcionar uma dose adequada de bactérias probióticas para que os efeitos desejáveis possam ocorrer.

Embora tem sido relatado um número significativo de espécies microbianas com potenciais propriedades probióticas, estabelecidas depois de pesquisas in vitro, préclínicas e/ou após estudos clínicos completos, apenas as cepas mais bem documentadas conseguem entrar no mercado. A maioria dos probióticos atuais são bactérias ácidoláticas, pertencentes aos gêneros Lactobacillus e Bifidobacterium. Nessa lista de microrganismos considerados probióticos são incluídos também fungos, algumas espécies de Bacillus, Clostridium, Propionibacterium e a Gram-negativa Escherichia $\operatorname{coli}(9)$.

Pesquisas contínuas estão promovendo o entendimento das interações complexas da flora normal e sua habilidade em resistir à invasão de bactérias patogênicas. A explosão de estudos envolvendo probióticos é demonstrada pelo aumento no número de publicações ao longo dos anos (de 176/ano em 2000 para 1476/ano em 2014) (10). Evidências crescentes tem mostrado que o consumo de probióticos pode potencializar o 
sistema imune do hospedeiro, bem como agir na prevenção/tratamento de certas doenças e/ou incômodos em humanos, tais como diarreia devido à infecção com Helicobacter pylori, má digestão de lactose e síndrome do intestino irritável. Além disso, atuam na prevenção do câncer de cólon e de bexiga, no controle dos níveis de colesterol e da hipertensão arterial, na proteção contra infecções do trato urinário e respiratório e na supressão de alergias (11-13).

Desde o início do século XXI, tem havido uma valorização crescente da microbiota bucal benéfica e seu uso na prevenção e tratamento da inflamação periodontal relacionada ao biofilme. A microbiota bucal é pelo menos tão complexa quanto a microbiota gastrointestinal ou vaginal. Além disso, os biofilmes dentários são considerados alvos terapêuticos difíceis. A visão atual sobre a etiologia da inflamação periodontal considera três fatores que determinam se a doença desenvolver-se-á em um sujeito (14): 1) um hospedeiro suscetível; 2) a presença de espécies patogênicas; 3) a redução ou ausência das chamadas bactérias benéficas. Do ponto de vista teórico, o aumento do número de bactérias benéficas por meio de probióticos pode ser de interesse considerável no tratamento de DPs. Os probióticos podem não apenas suprimir a emergência de patógenos endógenos e impedir a super-infecção com patógenos exógenos, mas também proteger o hospedeiro por meio da promoção de uma resposta imunoinflamatória benéfica (14).

No que se refere à saúde bucal, especificamente à saúde periodontal, pode-se constatar que a literatura já apresenta algumas evidências bastante contundentes a favor do uso de cepas bacterianas benéficas efetoras como estratégia de tratamento para as DPs (15-16). A modulação da microbiota do hospedeiro e a interação direta com o sistema imunológico são os mecanismos básicos que podem explicar os efeitos benéficos de probióticos na saúde periodontal. Estudos que avaliaram os efeitos dos probióticos no tratamento da DP demonstraram que os mesmos podem reduzir o número de periodontopatógenos, melhorar os parâmetros clínicos periodontais, diminuir os níveis de citocinas pró-inflamatórias e potencializar os efeitos da RAR (17-21).

Embora a literatura científica apresente resultados promissores, é importante considerar que os achados obtidos com probióticos não podem ser generalizados (22) uma vez que eles são dependentes da cepa, dosagem, freqüência e via de administração utilizadas. Os estudos que investigaram os efeitos dos probióticos nas DPs, até o presente momento, utilizaram principalmente microorganismos do gênero Lactobacillus. No entanto, outros probióticos potenciais merecem investigações. 
Bifidobacterium animalis subsp. lactis (B. lactis) compõe a microbiota humana e apresenta uma relação simbiótica com o hospedeiro. É considerado um potencial probiótico porque possui propriedades imunomoduladoras (23-25) e antimicrobianas (26-28).

Espécies do gênero Bifidobacterium são organismos comumente encontrados na cavidade bucal e a maioria das espécies está associada com a saúde do hospedeiro. Estudos utilizando métodos de cultura apontam que espécies do gênero Bifidobacterium estão entre os primeiros microrganismos anaeróbios a colonizar a cavidade bucal (29). De fato, espécies desse gênero bacteriano podem ser encontradas no leite materno, o que explica uma exposição precoce da cavidade bucal a essas bactérias $(30,31)$.

Considerando que contagens de espécies de Bifidobacterium no ambiente bucal podem estar associadas a saúde periodontal e ao progresso do tratamento em pacientes com periodontite (32), Oliveira et al. (33) investigaram os efeitos da administração tópica de Bifidobacterium animalis subsp lactis HN019 na periodontite experimental $(\mathrm{PE})$ em ratos. As análises microtomográficas realizadas demonstraram que os animais com DP induzida por ligadura e tratados por meio de irrigações subgengivais com microrganimos probióticos (grupo teste) apresentaram menores porosidade óssea, separação de trabéculas ósseas e perda de inserção conjuntiva, bem como maior volume ósseo que os animais que receberam irrigações subgengivais com uma solução sem probióticos (grupo controle). No grupo teste, as amostras de biofilme coletadas apresentaram maiores proporções de espécies semelhantes a Actinomyces e Streptococcus (espécies compatíveis com saúde periodontal), bem como menores proporções de espécies semelhantes à Veillonella parvula, Capnocytophaga sputigena, Eikenella corrodens e Prevotella intermedia (espécies envolvidas na patogênese da periodontite) quando comparadas àquelas do grupo controle. As análises de amostras de biofilme por meio de Reação em cadeia da polimerase (PCR) também confirmaram a presença da cepa probiótica HN019 nos animais do grupo teste. Considerando o perfil imunoinflamatório dos animais, o grupo teste apresentou maior expressão de osteoprotegerina (OPG) e de beta-defensinas (BD), bem como menores níveis de IL-1 $\beta$ e do ligante do receptor ativador do fator nuclear kappa beta (RANKL) nos tecidos gengivais do que o grupo controle.

De fato, a seleção das melhores cepas probióticas para a prevenção de doenças periodontais ainda é uma questão em aberto (34). Os resultados contraditórios observados entre os estudos apontam que nem todos os probióticos, a despeito de seus 
benefícios comprovados em outros ramos da saúde, promovem efeitos benéficos no tratamento das DPs. Portanto, parece necessária a realização de avaliações específicas para seleção de linhagens apropriadas (34). Estudos pré-clínicos validados utilizando modelos animais de periodontite podem fornecer novos dados importantes sobre a segurança e a eficácia de potenciais probióticos (35). Até o presente momento, os efeitos de B. lactis HN019 como terapia adjuvante à RAR para o tratamento da DP não foram investigados. 
Proposíção 


\section{Objetivo geral}

$\checkmark$ Avaliar os efeitos da administração do probiótico B. lactis HN019 como terapia adjuvante à RAR no tratamento da DP induzida por ligadura em ratos.

\section{Objetivos específicos}

Avaliar:

$\checkmark$ Volume ósseo e porosidade óssea presentes na região de bifurção dos $1^{\text {os }}$ molares inferiores por meio de análise com microtomografia computadorizada por transmissão de raios $\mathrm{X}$ (micro-CT);

$\checkmark \quad$ Nível de inserção conjuntiva na região interproximal entre o $1^{\circ}$ e $2^{\circ}$ molares inferiores e perda de osso alveolar na região de bifurção dos $1^{\text {os }}$ molares inferiores por meio de análise histométrica;

$\checkmark$ Expressão de IL-1 $\beta$, citocina quimioatraente para neutrófilos (CINC), IL-10, fator de crescimento transformador beta (TGF- $\beta$ ) e fosfatase ácida tartarato resistente (TRAP) nos tecidos periodontais por meio de reações imunohistoquímicas;

$\checkmark$ Altura de vilosidades (AV) e profundidade de criptas (PC) no intestino delgado;

$\checkmark \quad$ Números de unidades formadoras de colônia (UFC) de bactérias anaeróbias e aeróbias presentes no biofilme associado às ligaduras durante $\mathrm{o}$ desenvolvimento da DP. 
Materiais e Métodos 


\subsection{Apreciação ética}

A pesquisa foi realizada respeitando-se os princípios éticos da experimentação animal, bem como as normas para a prática didático-científica da vivissecção dos mesmos (Lei 11.794/2008), a Declaração Universal dos Direitos dos Animais da UNESCO (Organização das Nações Unidas para Educação, a Ciência e a Cultura), as normas da Sociedade Brasileira de Ciência em Animais de Laboratório e a legislação em vigor (Lei 9605/1998). Todos os procedimentos com animais foram aprovados pela Comissão de Ética no Uso de Animal (CEUA) da Faculdade de Odontologia de Ribeirão Preto (FORP) da Universidade de São Paulo (USP) (protocolo 13.1.136.53.5).

\subsection{Cálculo do tamanho da amostra}

O cálculo do tamanho amostral foi realizado pelo programa Graphpad Statemate 2.0 (GraphPad Software, Inc., San Diego, CA, EUA). O tamanho da amostra foi determinado para assegurar poder estatístico de $80 \%$ no reconhecimento de diferenças significativas entre os grupos em torno de $20 \%$ e desvio-padrão de $15 \%$ com um intervalo de confiança de $95 \%(\alpha=0,05)$, considerando as mudanças microtomográficas no volume ósseo (VO) da região de bifurcação do $1^{\circ}$ molar inferior como variável primária de resultado. Dessa forma, chegou-se a um tamanho amostral adequado de 8 animais por grupo experimental.

\subsection{Modelo experimental}

Foram utilizados 32 ratos, machos (Rattus norvegicus, albinus, Wistar), com idade entre 3 e 4 meses, pesando entre 250 e $300 \mathrm{~g}$ (Biotério da FORP-USP). Os animais foram acomodados em caixas de polipropileno autoclaváveis e submetidos a um período de 7 dias de aclimatação com o ambiente e com equipe de execução do projeto. A sala foi climatizada a uma temperatura de $22 \pm 2^{\circ} \mathrm{C}$ e com ciclos de $12 / 12$ horas claroescuro. Durante todo o experimento, os animais consumiram ração sólida selecionada e água ad libitum. Antes do estudo começar, os ratos foram identificados por um código numérico. De acordo com uma tabela numérica gerada com uso de um software em computador, cada rato foi alocado em um dos seguintes grupos $(n=8)$ : Grupo $C$ (controle); Grupo PROB (probiótico); Grupo PE-RAR (periodontite experimental + raspagem e alisamento radicular) e Grupo PE-RAR-PROB (periodontite experimental + raspagem e alisamento radicular + probiótico). A sequência de alocação foi mantida oculta para todos os investigadores do estudo (operadores, avaliadores de resultados e 
bioestaticista). Todas as análises foram, então, realizadas por examinadores calibrados que desconheciam os grupos experimentais do presente estudo.

\subsection{Indução da DP com ligadura}

No dia 0 do experimento, para a colocação da ligadura nos grupos PE-RAR e PE-RAR-PROB, os animais foram anestesiados por meio de injeção intraperitoneal, com solução de Cloridrato de Xilazina a 2\% (2mg/mL) (Rompum ${ }^{\circledR}$ - Bayer Saúde Animal, São Paulo, SP, Brasil) e Cloridrato de Ketamina a 10\% (10mg/mL) (Dopalen ${ }^{\circledR}$ - Ceva Saúde Animal Ltda., Paulínia, SP, Brasil) nas respectivas doses de 10 mg/Kg (Xilazina) e $80 \mathrm{mg} / \mathrm{Kg}$ (Ketamina). Após a anestesia geral, os animais foram posicionados em mesa operatória, a qual permitiu a manutenção da abertura bucal dos mesmos, facilitando o acesso aos dentes posteriores da mandíbula. Com o auxílio de porta agulha tipo castroviejo (Quinelato, Rio Claro, SP, Brasil) e sonda exploradora odontopediátrica (Golgran, São Paulo, SP, Brasil), foi colocado um fio de seda 4-0 (Ethicon, Johnson \& Johnson, São José dos Campos, SP, Brasil) ao redor dos $1^{\text {os }}$ molares inferiores esquerdo e direito de cada animal (Figura 1). A presença das ligaduras nos animais foi verificada periodicamente. Caso fosse observado perda da ligadura, um novo animal era preparado para o estudo.

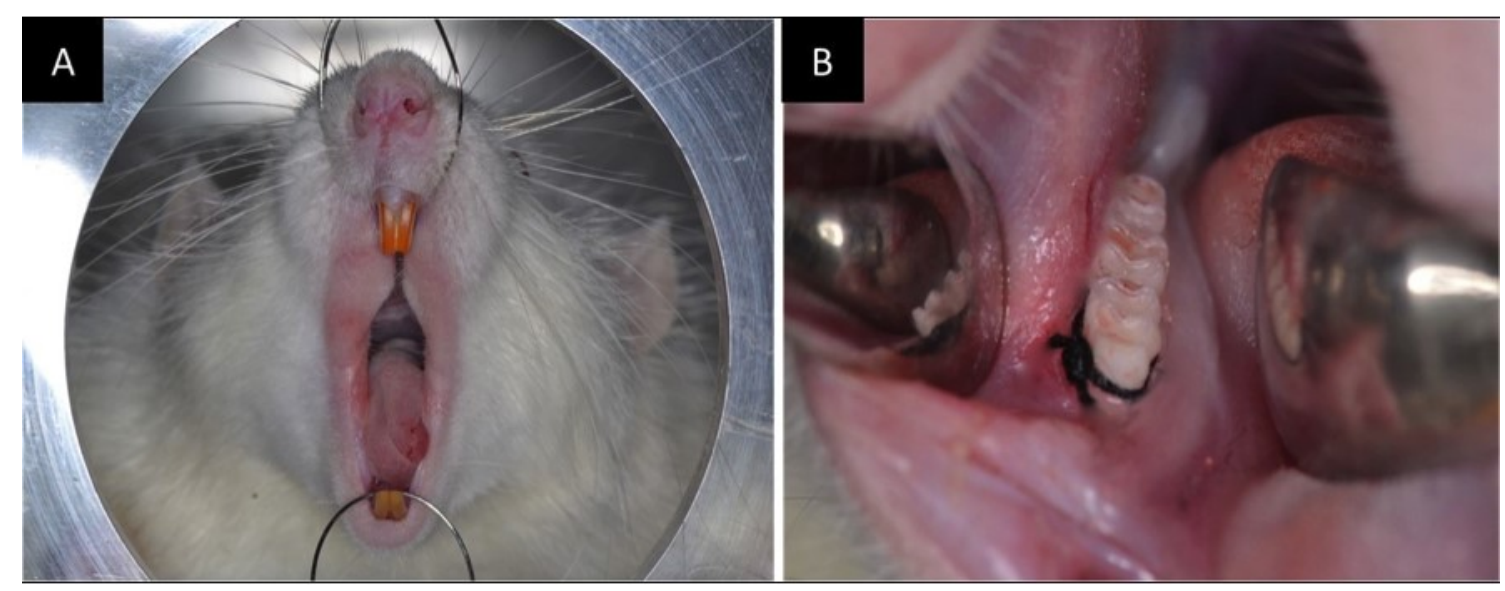

Figura 1 - (A) Animal posicionado para a colocação da ligadura; (B) Fio de seda em posição para indução da doença periodontal no $1^{\circ}$ molar inferior.

\subsection{Raspagem e Alisamento Radicular (RAR)}

As ligaduras foram removidas em todos os animais dos grupos PE-RAR e PERAR-PROB após 14 dias de sua instalação. Os molares foram, então, submetidos à RAR por meio de debridamento manual com a utilização de curetas mini-five \#1-2 (Hu- 
Friedy Co. Inc., Chicago, IL, EUA). Foram realizados 10 movimentos de tração, de distal para mesial, nas faces vestibular e lingual sob irrigação com solução salina estéril. A região de bifurcação e as áreas interproximais foram tratadas com as mesmas curetas por meio de movimentos de tração no sentido cérvico-oclusal (36). Todos os procedimentos de RAR foram realizados pelo mesmo operador.

\subsection{Administração da terapia probiótica}

No $14^{\circ}$ dia do experimento, foram administrados oralmente aos animais $10 \mathrm{~mL}$ de leite desnatado a 10\% (Molico ${ }^{\circledR}$, Nestlé Brasil Ltda., São Paulo, SP, Brasil), uma vez ao dia (às 8:00 horas), durante 15 dias. Para os grupos PROB e PE-RAR-PROB, o leite desnatado a 10\% foi inoculado com B. lactis HN019 (Howaru Bifidus Lyo 40 DCU, DuPont $^{\mathrm{TM}}$ Danisco ${ }^{\circledR} /$ Fermentech, São Paulo, SP, Brasil) de forma a se obter $10^{9}$ UFC/10 mL. No grupo PE-RAR-PROB, a terapia probiótica foi iniciada imediatamente após a RAR. Os animais dos grupos $\mathrm{C}$ e PE-RAR receberam $10 \mathrm{~mL}$ de leite desnatado a 10\% sem B. lactis HN019 (placebo).

\subsection{Eutanásia e coleta de material para análises}

Todos os animais foram submetidos à eutanásia 29 dias após início do experimento. A eutanásia foi realizada pela administração de uma dose letal (150 $\mathrm{mg} / \mathrm{Kg}$ ) de tiopentato de sódio (Thiopentax ${ }^{\circledR}$, Cristália Produtos Químicos Farmacêuticos Ltda., São Paulo, SP, Brasil). As hemimandíbulas foram dissecadas e coletadas. Amostras de partes distintas do intestino delgado (duodeno, jejuno, íleo) também foram removidas e armazenadas. Todas as peças coletadas foram fixadas em formaldeído a $4 \%$ durante 24 horas.

\subsection{Análise com microtomografia computadorizada por transmissão de raios $X$ (micro-CT)}

Espécimes não desmineralizadas (hemimandíbulas direitas) foram escaneados por um sistema de micro-CT de feixe cônico (Skyscan 1172, Bruker, Kontich, Bélgica). $\mathrm{O}$ gerador de raio-X foi operado com um potencial de aceleração de $60 \mathrm{kV}$, corrente de $165 \mu \mathrm{A}$ e tempo de exposição de $650 \mathrm{~ms}$ por projeção. As imagens foram produzidas com um tamanho de voxel de 6x6x6 $\mu \mathrm{m}$.

Usando um software apropriado (Data Viewer ${ }^{\circledR}$, versão 1.5.0, Bruker, Kontich, Bélgica), os 3 modelos tridimensionais gerados foram rotacionados em uma posição 
padrão, com os seguintes critérios: (1) no plano transaxial, o $1^{\circ}$ molar inferior teve o seu eixo em posição vertical, (2) no plano coronal, o osso mandibular foi verticalmente orientado, com a raiz mesial do $1^{\circ}$ molar inferior na posição superior da imagem e (3) no plano sagital, a superfície oclusal do $1^{\circ}$ molar inferior foi horizontalmente posicionada. Medidas lineares foram realizadas em quatro locais diferentes: vestibular, lingual, interproximais e região de bifurcação. Para sítios vestibulares, linguais e interproximais, foram mensuradas as distâncias lineares $(\mu \mathrm{m})$ da junção cementoesmalte (JCE) à crista óssea alveolar (CO) (37). Para os sítios interproximais, os dados foram analisados utilizando o software CT-Analyser ${ }^{\circledR}$ (CT-Analyser ${ }^{\circledR}$, versão 1.13.5.1+, Bruker, Kontich, Bélgica). Na região de bifurcação, foi mensurada a distância $(\mu \mathrm{m})$ entre o centro do teto da bifurcação e a CO. As quatro medidas lineares obtidas em cada animal foram somadas para expressar o valor do nível ósseo alveolar (NOA) (Figura 2).

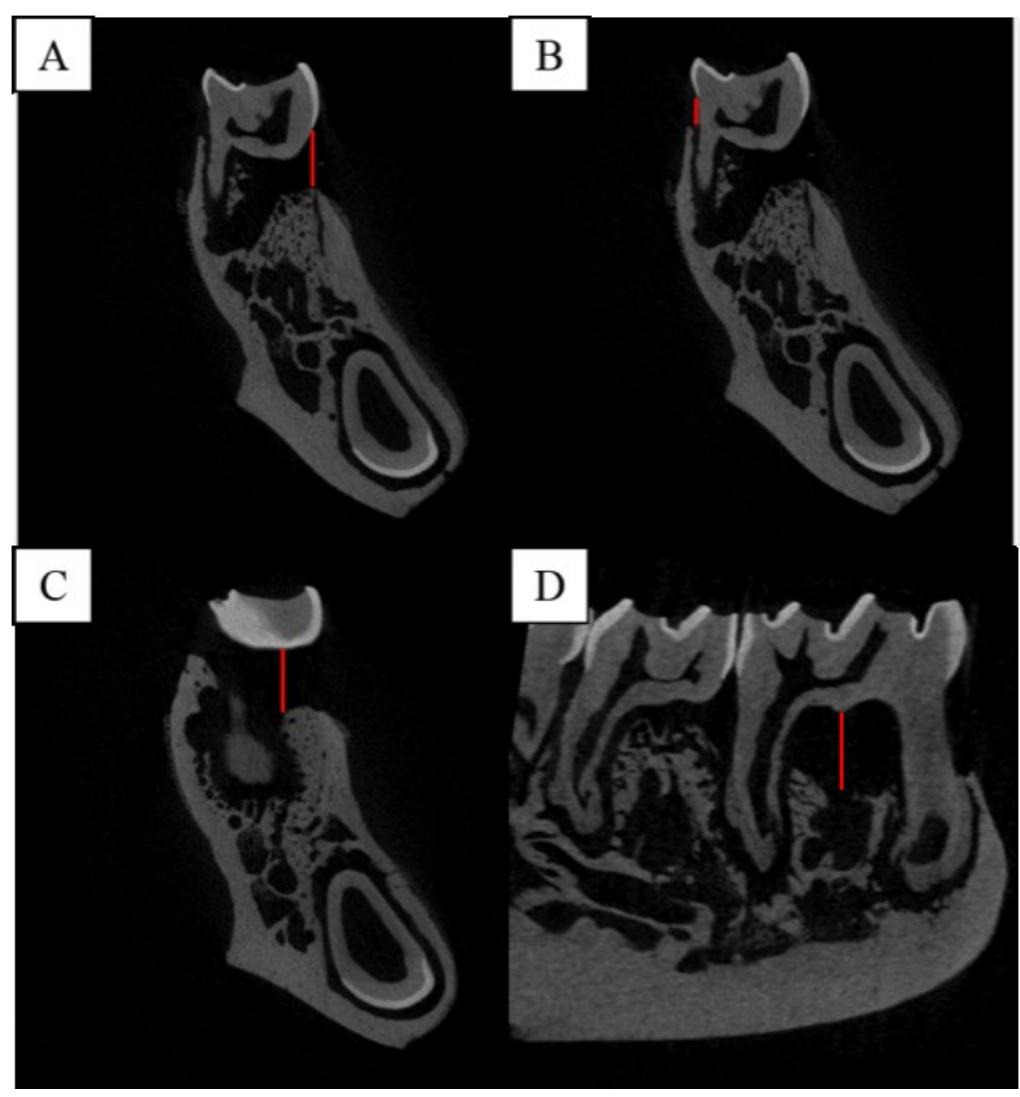

Figura 2 - Medidas lineares (linhas vermelhas) das distâncias $(\boldsymbol{\mu m})$ entre a junção cemento-esmalte e a crista óssea alveolar realizadas nos cortes microtomográficos visualizados no eixo transaxial (A - vestibular; $\mathbf{B}$ - lingual; $\mathbf{C}$ - interproximal) e no eixo sagital (D - bifurcação). 
As análises volumétricas foram realizadas com o software CT-Analyser ${ }^{\circledR}$ na região de bifurcação do $1^{\circ}$ molar inferior. As imagens foram visualizadas no eixo coronal e o intervalo de cortes analizados seguiu os seguintes parâmetros: i) utilizou-se como ponto de partida para a análise o corte microtomográfico no qual as quatro raízes do primeiro molar inferior estavam completamente separadas; ii) o corte microtomográfico final foi determinado como aquele em que não era possível visualizar mais o osso inter-radicular na região de bifurcação do $1^{\circ}$ molar inferior. O retângulo foi a figura geométrica escolhida para representar a região de interesse a ser analisada. Esta forma geométrica foi adequada por interpolação à área a ser medida e posterior determinação do volume de interesse (VOI) (Figura 3). Em seguida, procedeu-se a binarização da imagem para a separação das estruturas óssea e dentária (por diferença de densidade), utilizando uma escala de níveis de cinza (limite inferior - 65 e limite superior - 255; grayscale threshold 0-255). Este padrão de binarização foi usado para todas as amostras. Os seguintes parâmetros foram determinados na análise volumétrica: a) VO: percentual do VOI preenchido com tecido ósseo e b) Porosidade Óssea (PO): percentual de porosidades presentes no tecido ósseo determinado no VOI.

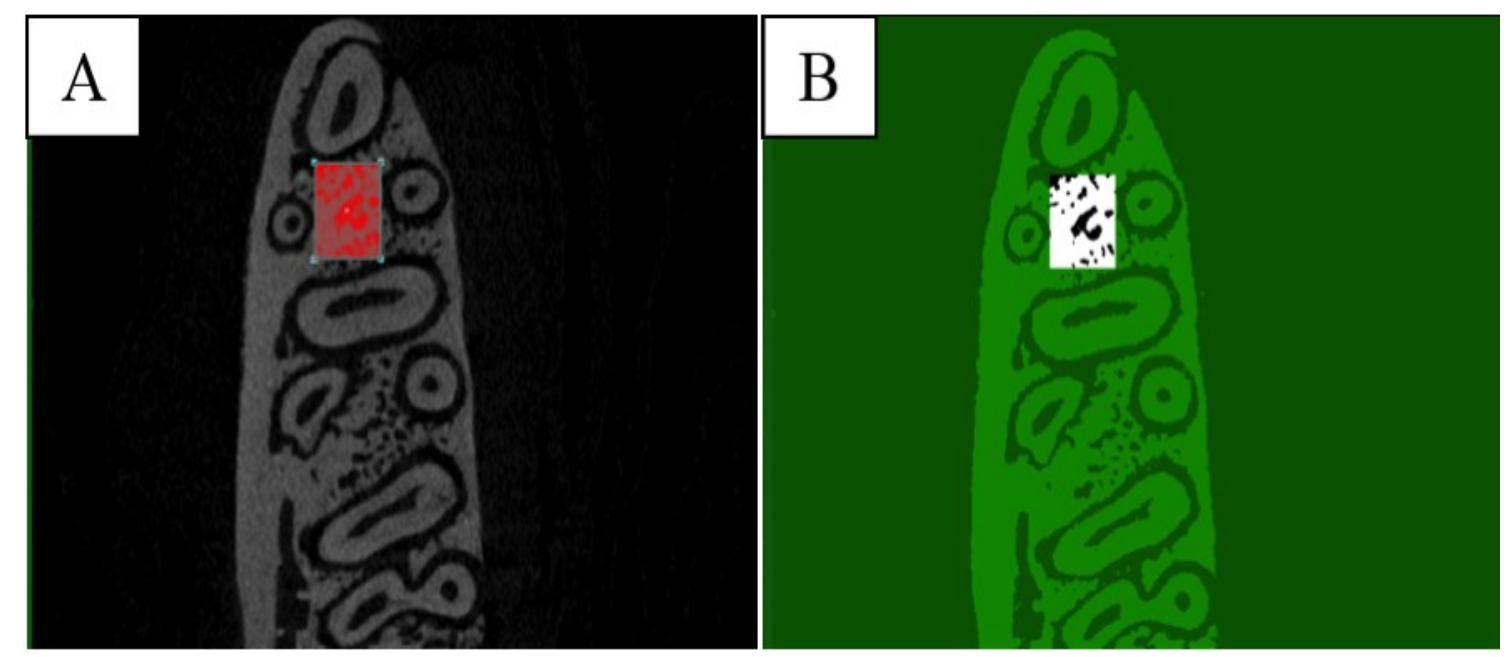

Figura 3 - Medidas volumétricas realizadas na região de bifurcação do $1^{\circ}$ molar inferior em cortes microtomográficos visualizados no eixo coronal. (A) A região de interesse a ser analisada (ROI) foi delimitada por um retângulo que tangenciava as quatro raízes do $1^{\circ}$ molar inferior. (B) As imagens foram binarizadas para separação das estruturas óssea e dentária (por diferença de densidade), utilizando uma escala de níveis de cinza (grayscale threshold 0-255). 


\subsection{Análise histomorfométrica dos tecidos periodontais}

As hemimandíbulas esquerdas foram descalcificadas por meio de solução de ácido etilenodiamino tetra-acético (EDTA) a 4\% durante 90 dias. Após este período, as peças foram desidratadas em álcool absoluto, diafanizadas em xilol e incluídas em parafina. Foram realizados, então, cortes seriados com $4 \mu \mathrm{m}$ de espessura, no plano mésio-distal.

Dois cortes histológicos de cada espécime, representando a porção vestíbulolingual central da hemimandíbula, foram corados utilizando a técnica de Hematoxilina e Eosina (HE). Com auxílio de microscopia de luz, foram analisadas as condições histopatológicas dos tecidos periodontais na região de bifurcação do $1^{\circ}$. molar inferior, considerando: conteúdo do infiltrado inflamatório periodontal, extensão da inflamação, padrão do tecido conjuntivo e perfil do osso alveolar presente.

Para análise histométrica, as imagens dos cortes histológicos foram capturadas por uma câmera digital acoplada a um microscópio de luz. Mensurações padronizadas foram determinadas com o auxílio de um sistema de análise de imagens digitalizadas e software específico (ImageLab 2000, Diracon Bio Informática Ltda., Vargem Grande do Sul, SP, Brasil). Foram realizadas, na raiz distal do $1^{\circ}$ molar inferior, medidas linerares para avaliar o nível de inserção conjuntiva (NIC), o qual foi calculado mensurando-se em mm a distância entre a JCE e a inserção conjuntiva (Figura 4). Na região de bifurcação do $1^{\circ}$ molar mandibular foi também calculada a área sem osso alveolar (ASOA) em $\mathrm{mm}^{2}$ (Figura 4). Para cada animal, foi obtida uma média dos valores dos dois cortes analisados.

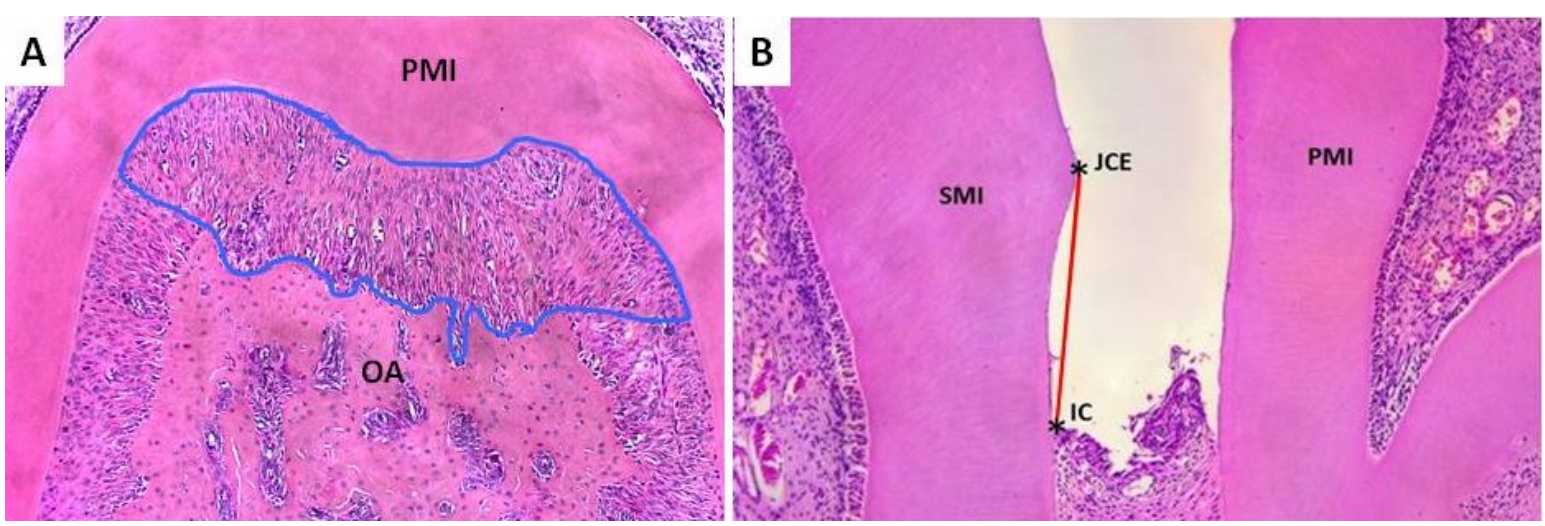

Figura 4 - Análise Histomorfométrica - imagem ilustrativa dos tecidos periodontais da região de bifurcação (A) e da região interproximal (B) entre o $1^{\circ}$ e $2^{\circ}$ molares inferiores de animais com doença periodontal. A linha vermelha representa a medida linear $(\mathrm{mm})$ do nível de inserção conjuntiva na região interproximal. A linha azul delimita a área sem osso alveolar na região de bifurcação. Coloração: Hematoxilina e Eosina. Aumento original $=10 x . J C E=$ junção cemento-esmalte; $\mathrm{OA}=$ osso alveolar; $\mathrm{IC}=$ inserção conjuntiva; $\mathrm{PMI}=$ primeiro molar inferior; $\mathrm{SMI}=$ segundo molar inferior. 


\subsection{Análise imunohistoquímica dos tecidos periodontais}

Os cortes histológicos (obtidos conforme descrição do item 3.9) foram desparafinizados em xilol e hidratados em série decrescente de etanol $\left(100^{\circ}-100^{\circ}\right.$ $\left.100^{\circ}-90^{\circ}-70^{\circ} \mathrm{GL}\right)$. A recuperação antigênica foi realizada através da imersão das lâminas histológicas em tampão citrato, pH 6 (Spring Bioscience ${ }^{\circledR}$, Pleasanton, CA, EUA), em câmara pressurizada (Decloaking chamber ${ }^{\circledR}$, Biocare Medical, Concord, CA, EUA) a $95^{\circ} \mathrm{C}$, por 20 minutos. No final de cada etapa da reação imunohistoquímica, as lâminas histológicas foram lavadas em tampão fosfato salino (PBS) 0,1 M, pH 7,4. Posteriormente, as lâminas foram imersas em 3\% de peróxido de hidrogênio por 1 hora e $1 \%$ de soro albumina bovino por 12 horas para bloqueio da peroxidase endógena e dos sítios inespecíficos, respectivamente.

As lâminas histológicas contendo amostras de todos os grupos experimentais foram incubadas com um dos seguintes anticorpos primários: anti-IL-1 $\beta$ de rato gerado em coelho (1:100-Rabbit anti-IL-1 $\beta$-SC 7884, Santa Cruz Biotechnology, Santa Cruz, CA, EUA), anti-CINC de rato gerado em cabra (1:100-Goat anti-CINC1-ab 10365, abcam ${ }^{\circledR}$, Cambridge, MA, EUA), anti-IL-10 de rato gerado em cabra (1:100-Goat AntiIL-10-SC 1783, Santa Cruz Biotechnology), anti-TGF- $\beta 1$ de rato gerado em coelho (1:200-Rabbit anti-TGF- $\beta 1$-SC 146, Santa Cruz Biotechnology) ou anti-TRAP de rato gerado em cabra (1:100-Cabra anti-TRAP-SC 30833, Santa Cruz Biotechnology). As seções histológicas foram avaliadas sob microscopia de luz com um microscópio óptico (Axiovision 4.8.2, Carl Zeiss MicroImaging GmbH, Jena, Alemanha).

Uma análise quantitativa de células positivas para TRAP e análises semiquantitativa da expressão de IL-1 $\beta$, CINC, IL-10 e TGF- $\beta 1$ foram conduzidas em toda a região de furca com aumento de 400x. Para as análises semi-quantitativas, foram determinados os seguintes escores: escore 0 - sem imunomarcação (ausência total de imunorreatividade na área); escore 1 - baixo padrão de imunomarcação $(\approx 1 / 3$ da área apresentando imunorreatividade); escore 2 - moderado padrão de imunomarcação $(\approx 2 / 3$ da área apresentando imunorreatividade) e escore 3 - alto padrão de imunomarcação (quase a totalidade da área apresentando imunorreatividade). O grupo controle foi usado como ponto de referência para se definir o padrão basal de imunorreatividade, a partir do qual os escores foram atribuídos aos demais grupos experimentais. 


\subsection{Análise histomorfométrica do intestino delgado}

As amostras de intestino delgado foram processadas rotineiramente e incluídas em parafina para a realização de cortes seriados com $6 \mu \mathrm{m}$ de espessura. Os cortes obtidos foram corados com HE para análise com microscopia de luz.

Para a análise histométrica, três cortes com vilosidades orientadas perpendicularmente à camada muscular intestinal foram selecionados de cada uma das amostras de duodeno, jejuno e íleo. As imagens dos cortes histológicos foram capturadas por uma câmera digital acoplada a um microscópio óptico e salvas em um computador. Com o auxílio do software "ImageLab 2000" (Diracon Bio Informática Ltda.) as seguintes medidas foram realizadas: i) Altura de Vilosidades (AV) mensuração da distância vertical do topo da vilosidade até a junção vilosidade-cripta em 10 vilosidades por corte histológico; ii) Profundidade de Cripta (PC) - mensuração da distância vertical da junção cripta-vilosidade até o limite mais inferior da cripta em 10 criptas por corte histológico. Os valores de AV e PC de cada animal foram representados pela média dos valores obtidos com a análise dos três cortes histológicos.

\subsection{Efeitos de B. lactis HN019 na microbiota associada às ligaduras}

Foram utilizados 12 ratos Wistar machos adultos (Rattus norvegicus, albinus), pesando 230-250 g, não utilizados nas experiências descritas anteriormente. Os animais foram divididos em grupos Placebo $(n=6)$ e Teste $(n=6)$. Uma ligadura de algodão foi colocada ao redor de seus $1^{\text {os }}$ molares inferiores direitos, conforme descrito por Messora et al. (38). Os animais receberam leite desnatado a $10 \%\left(\right.$ Molico $^{\circledR}$ ) uma vez ao dia durante 15 dias. No grupo teste, o leite foi inoculado com cultura de B. lactis HN019 (Howaru Bifidus Lyo $40 \mathrm{DCU}$ ) a fim de se obter $10^{9} \mathrm{UFC} / 10 \mathrm{~mL}$.

As ligaduras dos animais foram removidas no $15^{\circ}$ dia do experimento e incubadas sob condições de aerobiose e anaerobiose durante 7 dias a $35^{\circ} \mathrm{C}$ para a contagem de UFC totais cultiváveis (39). A razão média obtida pela divisão do número total de UFC de bactérias aeróbicas pelo número total de UFC de bactérias anaeróbicas foi, então, calculada em cada grupo experimental.

\subsection{Validação da RAR como tratamento da PE}

Com o intuito de verificar a eficácia dos procedimentos de RAR para tratamento da PE, 12 animais foram submetidos à indução da DP conforme descrito anteriormente. As ligaduras foram removidas após 14 dias de sua instalação. Enquanto nos $1^{\text {os }}$ molares 
inferiores direitos nenhum procedimento de RAR foi executado, os 1os molares esquerdos foram submetidos à RAR conforme descrição do item 3.5. Os animais foram submetidos à eutanásia aos 29 dias pós-operatórios (15 dias após a remoção das ligaduras). As hemimandíbulas foram dissecadas, divididas, fixadas em formol neutro a 10\% por 48 horas e processadas conforme descrição do item 3.9 para mensuração de ASOA e NIC.

\subsection{Variáveis de resultado}

Foi definida como variável primária deste estudo as diferenças entre os grupos obtidas na análise microtomográfica de VO. Os demais parâmetros microtomográficos histomorfométricos, imunohistoquímicos e microbiológicos foram definidos como variáveis secundárias.

\subsection{Análise estatística}

As análises foram realizadas com o software Bioestat (BioEstat, Versão 5.3. Instituto de Desenvolvimento Sustentável Mamirauá, Amazonas, Brasil). O animal foi considerado como a unidade estatística. Foi adotado nível de significância de 5\% ( $p<$ 0,05). Os dados foram agrupados e apresentados como médias e desvios-padrão (variáveis contínuas) ou medianas, desvios interquartílicos e valores máximos e mínimos (variáveis ordinais). A distribuição dos dados foi verificada pelo teste ShapiroWilk. Para os dados que apresentaram distribuição normal, foram selecionados testes paramétricos para análises das diferenças intergrupos. Testes não paramétricos foram aplicados para os dados com distribuição não normal.

Todas as avaliações histométricas, imunohistoquímicas, microbiológicas e microtomográficas foram realizadas por examinadores calibrados. Para calibração dos examinadores, um terço da amostra foi avaliada em dois períodos de tempo com um intervalo de 48 horas. O coeficiente de correlação intraclasse (CCI) foi utilizado para determinar a reprodutibilidade dos examinadores nas duas avaliações realizadas. Valores de CCI maiores que $90 \%$ foram considerados para assegurar a calibração dos examinadores.

A significância das diferenças entre os grupos para ASOA, NOA, VO, PO, número de células TRAP-positivas, AV e PC foi determinada pela análise de variância (ANOVA) seguida pelo teste post-hoc de Tukey. Teste t de Student foi utilizado para análise de NIC. Para análise dos dados imunohistoquímicos referentes ao padrão de 
imunomarcação de IL-1 $\beta$, CINC, IL-10 e TGF- $\beta 1$, a significância das diferenças entre os grupos foi determinada pelo teste de Kruskal-Wallis, seguido pelo teste post-hoc de Dunn. A diferença entre os grupos para a razão entre bactérias aeróbias/anaeróbias foi avaliada pelo Teste t de Student. Para validação do modelo de RAR no tratamento da PE, o Teste $\mathrm{t}$ de Student de amostras pareadas foi utilizado para determinar a significância das diferenças nos valores de ASOA entre molares tratados e não tratados comRAR. 
Resultados 


\subsection{Análise com microtomografia computadorizada por transmissão de raios $X$ (micro-CT)}

O grupo PE-RAR-PROB apresentou maior VO e menores PO e NOA quando comparado ao Grupo PE-RAR $(p<0,05)$. As médias e os desvios padrão de VO, PO e NOA, bem como as comparações intergrupos, estão apresentados na Tabela 1.

Tabela 1 - Análises com micro-CT. Médias e desvios padrão (DP) de VO (\%), PO (\%) e NOA ( $\mu$ m) dos grupos C, PROB, PE-RAR e PE-RAR-PROB, com comparações entre os grupos.

\begin{tabular}{|c|c|c|c|c|}
\hline \multirow[t]{3}{*}{ VARIÁVEL } & \multicolumn{4}{|c|}{ GRUPOS EXPERIMENTAIS } \\
\hline & $\begin{array}{c}\mathbf{C} \\
\mathrm{N}=8\end{array}$ & $\begin{array}{c}\text { PROB } \\
\mathrm{N}=8\end{array}$ & $\begin{array}{c}\text { PE-RAR } \\
\mathrm{N}=8\end{array}$ & $\begin{array}{c}\text { PE-RAR-PROB } \\
\mathrm{N}=8\end{array}$ \\
\hline & Média \pm DP & Média \pm DP & Média \pm DP & Média \pm DP \\
\hline VO (\%) & $80,3 \pm 9,3^{*}$ & $83,9 \pm 2,5^{*}$ & $31,8 \pm 14,1$ & $67,1 \pm 20,9^{*}$ \\
\hline PO (\%) & $19,3 \pm 9.3^{*}$ & $17,1 \pm 2,9^{*}$ & $70,5 \pm 16,9$ & $22,8 \pm 17,8^{*}$ \\
\hline NOA (um) & $1537 \pm 331,8^{*}$ & $1754 \pm 610.9^{*}$ & $4682 \pm 1634$ & $2853 \pm 820,6^{*}$ \\
\hline
\end{tabular}

*Diferença significativa quando comparado ao Grupo PE-RAR $(p<0,05)$

$\mathrm{VO}=$ volume ósseo; $\mathrm{PO}=$ porosidade óssea; $\mathrm{NOA}=$ nível ósseo alveolar. 


\subsection{Análise histomorfométrica dos tecidos periodontais}

\subsubsection{Análise histopatológica}

Nos grupos C e PROB, o ligamento periodontal apresentou grande quantidade de fibras colágenas, fibroblastos e vasos sanguíneos. As fibras colágenas estavam inseridas no cemento e no osso alveolar. O tecido ósseo da região de bifurcação apresentava algumas pequenas irregularidades em sua superfície (Figuras 5C, D). Em ambos os grupos, foram observadas integridades de epitélio juncional e sulcular na área interproximal (Fig. 5G, H).

No grupo PE-RAR, o tecido conjuntivo apresentou infiltrado inflamatório moderado constituído principalmente por neutrófilos na região de bifurcação. O osso do septo interradicular apresentou contornos externos irregulares (Fig. 5E) devido à presença de numerosos osteoclastos ativos. Um dano severo do epitélio juncional e sulcular foi observado na área interproximal (Fig. 5I).

No grupo PE-RAR-PROB, o infiltrado inflamatório na região de bifurcação foi composto principalmente por neutrófilos e estava menos extenso do que aquele observado no grupo PE-RAR. O tecido ósseo no septo interradicular apresentou contorno externo irregular e estava coberto com osteoblastos ou células de revestimento ósseo. Poucos osteoclastos ativos foram observados. Neoformação óssea na região de bifurcação foi observada na maioria dos espécimes (Fig. 5F). Os epitélios juncional e sulcular da área interproximal estavam menos lesionados que aqueles do grupo PE-RAR (Fig. 5J).

\subsubsection{Análise histométrica}

Os grupos com PE-RAR e PE-RAR-PROB apresentaram maior reabsorção óssea alveolar e perda de inserção conjuntiva do que os grupos $\mathrm{C}$ e $\operatorname{PROB}(p<0,05$, Figuras 5A, B). Estes últimos não apresentaram nenhuma perda de inserção conjuntiva. Quando comparado com o grupo PE-RAR, o grupo PE-RAR-PROB apresentou menores ASOA e NIC $(p<0,05$, Figuras 5A, B). 

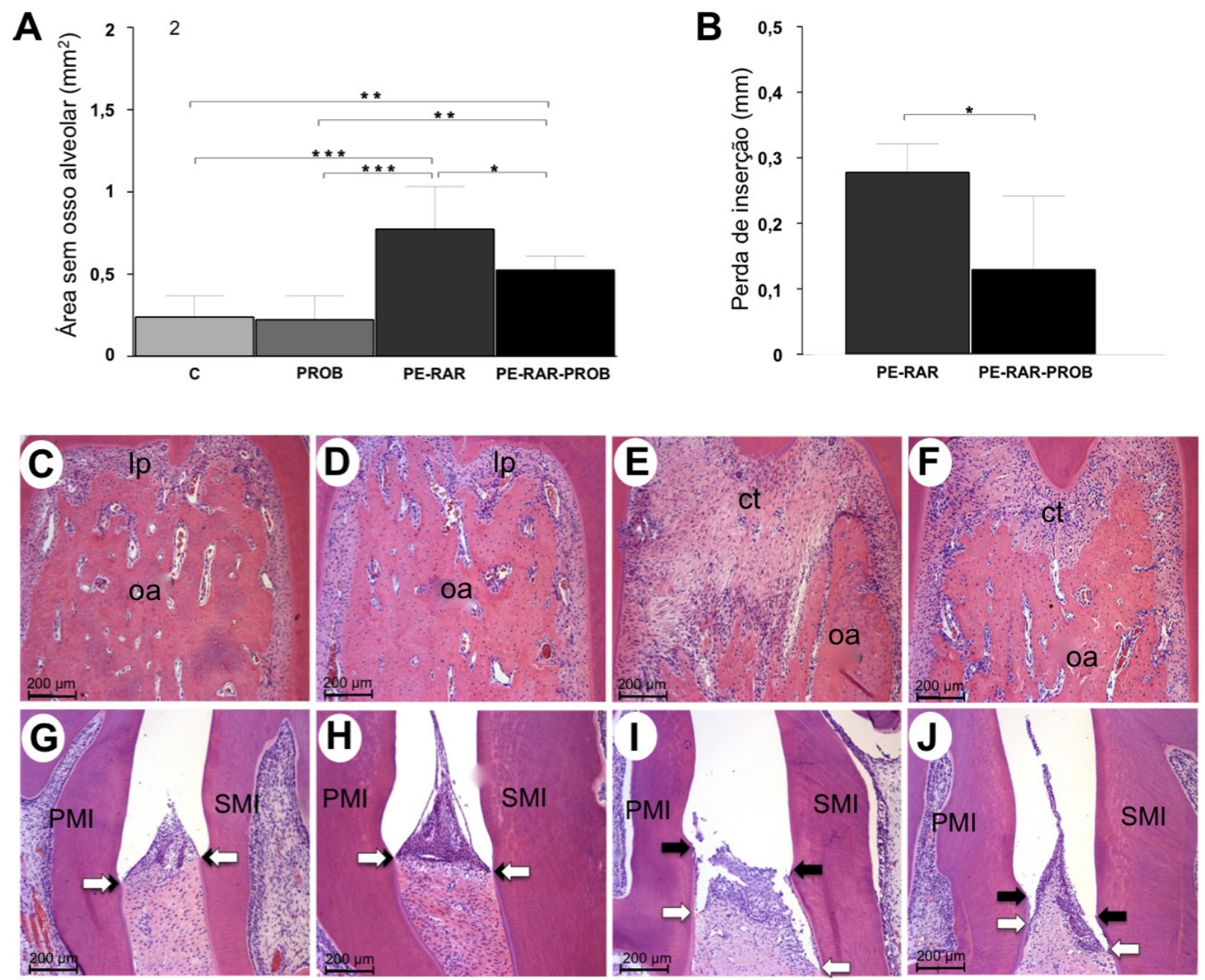

Figura 5 - Análise histomorfométrica dos tecidos periodontais. Médias e desvios padrão de ASOA (A, área de bifurcação) e NIC (B, área interproximal), com comparações entre grupos. Fotomicrografias dos tecidos periodontais na região de bifurcação $(\mathbf{C}-\mathbf{F})$ e áreas interproximais $(\mathbf{G}-\mathbf{J})$ dos $1^{\text {os }}$ molares inferiores: Grupo C (C e G); Grupo PROB (D e H); Grupo PE-RAR (E e I); Grupo PE-RAR-PROB (F e J). Abreviaturas e símbolos: oa = osso alveolar; $\mathrm{tc}=$ tecido conjuntivo; $\mathrm{lp}=$ ligamento periodontal; ASOA $=$ área sem osso alveolar; $\mathrm{NIC}=$ nível de inserção conjuntiva; $\mathrm{PMI}=$ primeiro molar inferior; $\mathrm{SMI}=$ segundo molar inferior; Setas pretas $=$ junção cemento-esmalte; Setas brancas $=$ inserção epitelial; $*=p<0,05 ; * *=p<0,01 ; * * *=$ $p<0,001$. Barras de escala: $\mathrm{C}-\mathrm{J}=200 \mu \mathrm{m}$. (Hematoxilina e Eosina). 


\subsection{Análise imunohistoquímica}

O número de células multinucleadas TRAP-positivas foi maior nos grupos PERAR e PE-RAR-PROB quando comparado aos grupos C e PROB ( $p<0,05$, Fig. 6). O grupo PE-RAR-PROB apresentou menos células multinucleadas TRAP-positivas que o grupo PE-RAR ( $p<0,05$, Fig. 6).

O grupo PE-RAR-PROB apresentou padrões de imunomarcação mais baixos para IL-1 $\beta$ e CINC (Fig. 7) e padrões de imunomarcação superiores para TGF- $\beta 1$ e IL10 (Figura 8) quando comparado ao Grupo PE-RAR $(p<0,05)$.

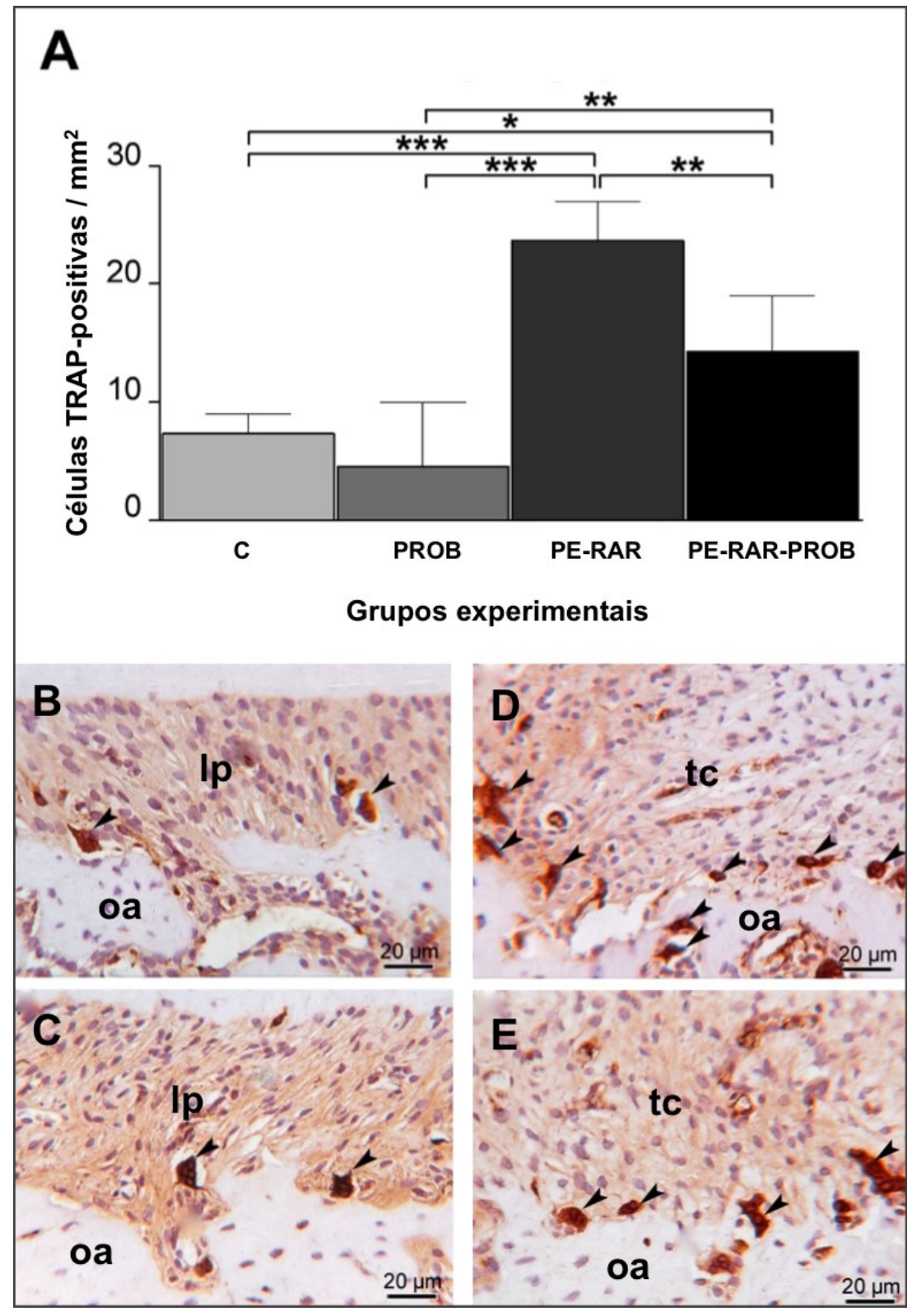

Figura 6 - Análise imunohistoquímica - TRAP. Médias e desvios padrão do número de células multinucleadas positivas para TRAP (A), com comparações entre grupos. Fotomicrografias mostrando imunomarcação para TRAP (B-E) na região de bifurcação dos $1^{\text {os }}$ molares inferiores: Grupo C (B); Grupo PROB (C); Grupo PE-RAR (D); Grupo PE-RAR-PROB (E). Abreviaturas e símbolos: oa = osso alveolar; tc $=$ tecido conjuntivo; $\mathrm{lp}=$ ligamento periodontal; Seta preta $=$ célula multinucleada TRAP-positiva; $*=p$ $<0,05 ; * *=p<0,01 ; * * *=p<0,001$. Barras de escala: $\mathrm{B}-\mathrm{E}=20 \mu \mathrm{m}$. (Contra-coloração com hematoxilina). 

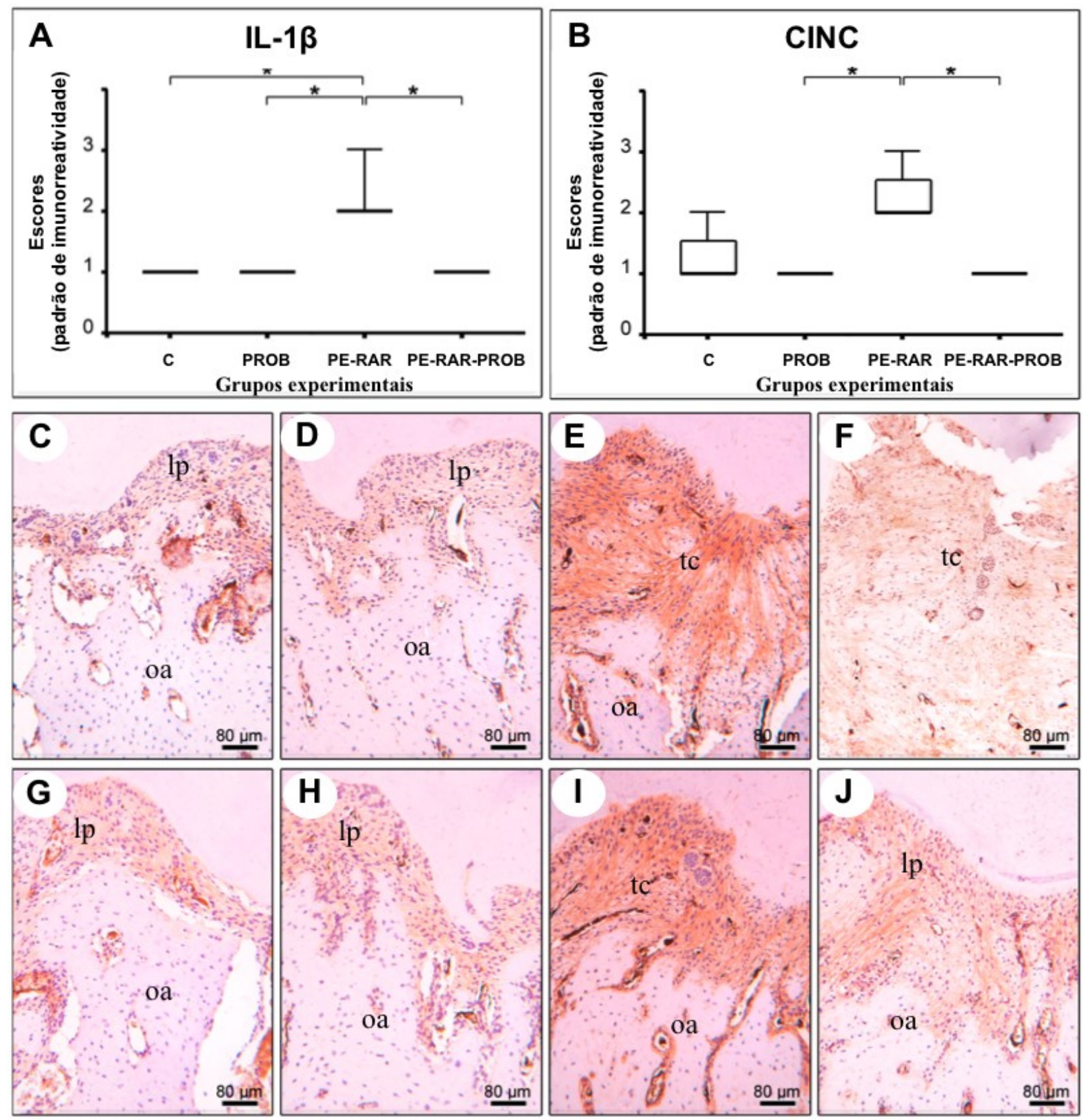

Figura 7 - Análise imunohistoquímica - IL-1 $\beta$ e CINC. Medianas, intervalo interquartil e valores máximos e mínimos dos escores de imunomarcação para IL-1 $\beta$ (A) e CINC (B), com comparações entre os grupos. Fotomicrografias mostrando imunomarcação para IL-1 $\beta$ (C-F) e CINC (G-J) nas áreas de bifurcação dos $1^{\text {os }}$ molares inferiores: Grupo C (C e G); Grupo PROB (D e H); Grupo PE-RAR (E e I); Grupo PE-RAR-PROB (F e $\mathrm{J})$. Abreviaturas e símbolos: oa $=$ osso alveolar; tc $=$ tecido conjuntivo; $\mathrm{lp}=$ ligamento periodontal; $*=p<0,05$. Barras de escala: C-J = $80 \mu \mathrm{m}$. (Contra-coloração com hematoxilina). 

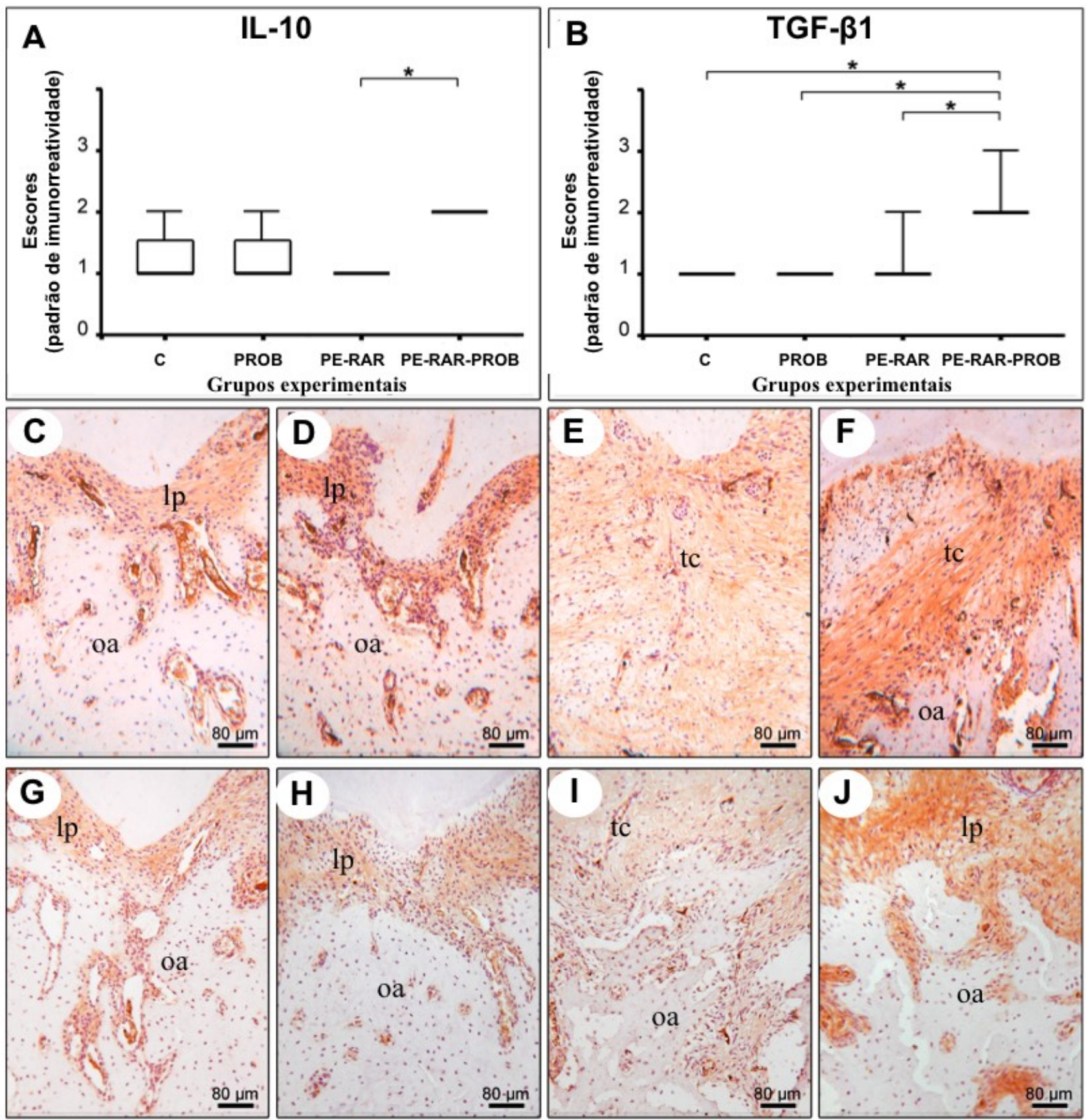

Figura 8 - Análises imunohistoquímicas - IL-10 e TGF- $\beta 1$. Medianas, intervalo interquartil e valores máximos e mínimos dos escores de imunomarcação para IL-10 (A) e TGF- $\beta 1$ (B), com comparações entre os grupos. Fotomicrografias mostrando imunomarcação para IL-10 (C-F) e TGF- $\beta 1$ (G-J) nas áreas de bifurcação dos $1^{\text {os }}$ molares inferiores: Grupo C (C e G); Grupo PROB (D e H); Grupo PE-RAR (E e I); Grupo PE-RAR-PROB (F e J). Abreviaturas: oa $=$ osso alveolar; $\mathrm{tc}=$ tecido conjuntivo; $\mathrm{lp}=$ ligamento periodontal; $*=p<0,05$. Barras de escala: $\mathrm{C}-\mathrm{J}=80 \mu \mathrm{m}$. (Contra-coloração com hematoxilina). 


\subsection{Análise histomorfométrica do intestino delgado}

\subsubsection{Análise histopatológica}

Em todos os grupos foi observada estrutura intestinal normal com uma camada mucosa apresentando vilosidades revestidas por epitélio simples cilíndrico, células calciformes e presença de criptas de Lieberkühn. A lâmina própria, logo abaixo do epitélio de revestimento da mucosa, estava constituída por tecido conjuntivo frouxo que se estendia até a muscular da mucosa, bem como apresentava glândulas tubulosas, células linfoides e intensa vascularização. Nos grupos PROB e PE-RAR-PROB, as criptas de Lieberkühn e vilosidades estavam mais desenvolvidas e apresentavam maior número de células calciformes do que os demais grupos nas amostras de duodeno (Figura 9), jejuno e íleo.

\subsubsection{Análise histométrica}

O Grupo PROB apresentou maior AV (Fig. 9A) e PC (Fig. 9B) em amostras de duodeno, jejuno e íleo que os outros grupos $(p<0,05)$. O Grupo PE-RAR demonstrou AV maior que o Grupo $\mathrm{C}$ em amostras de íleo $(p<0,05)$. O Grupo PE-RAR-PROB apresentou PC maior em amostras de duodeno e jejuno que o Grupo PE-RAR $(p<0,05)$. 

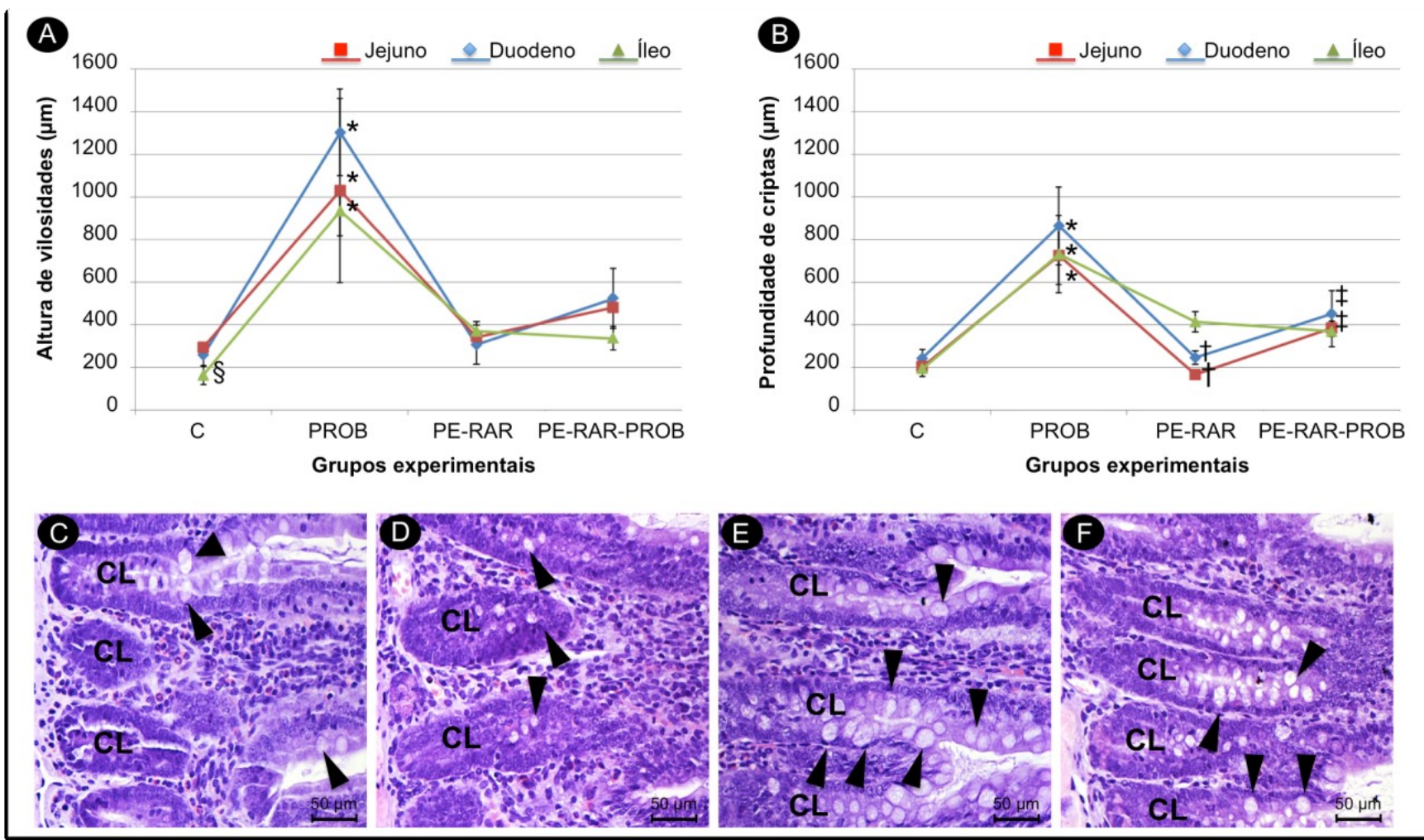

Figura 9 - Análise histomorfométrica do intestino delgado. Valores médios e desvios padrão de AV (A) e PC (B) em seções intestinais, com comparações entre os grupos. Fotomicrografias do intestino delgado (seções do duodeno): Grupo C (C); Grupo PE-RAR (D); Grupo PROB (E); Grupo PE-RAR-PROB (F). Abreviaturas e símbolos: CL = cripta de Lieberkühn; AV = altura de vilosidades; $\mathrm{PC}=$ profundidade da criptas; Seta preta = células calciformes; $*=\mathrm{Diferença}$ significativa $(p<0,05)$ quando comparado com os Grupos $\mathrm{C}$, PE-RAR e PE-RAR-PROB; $\dagger=$ Diferença significativa $(p$ $<0,05)$ entre os grupos PE-RAR e PE-RAR-PROB; $+=$ Diferença significativa $(p<0,05)$ entre os grupos C e PE-RARPROB; $\S=$ Diferença significativa $(p<0,05)$ entre os grupos $\mathrm{C}$ e PE-RAR. Barras de escala: C-F $=50 \mu \mathrm{m}$. (Hematoxilina e Eosina). 


\subsection{Efeitos de B. lactis HN019 na microbiota associada às ligaduras}

A proporção entre bactérias aeróbias e anaeróbias (Fig. 10) foi maior no Grupo Teste quando comparado com o Grupo Placebo $(p<0,05)$.

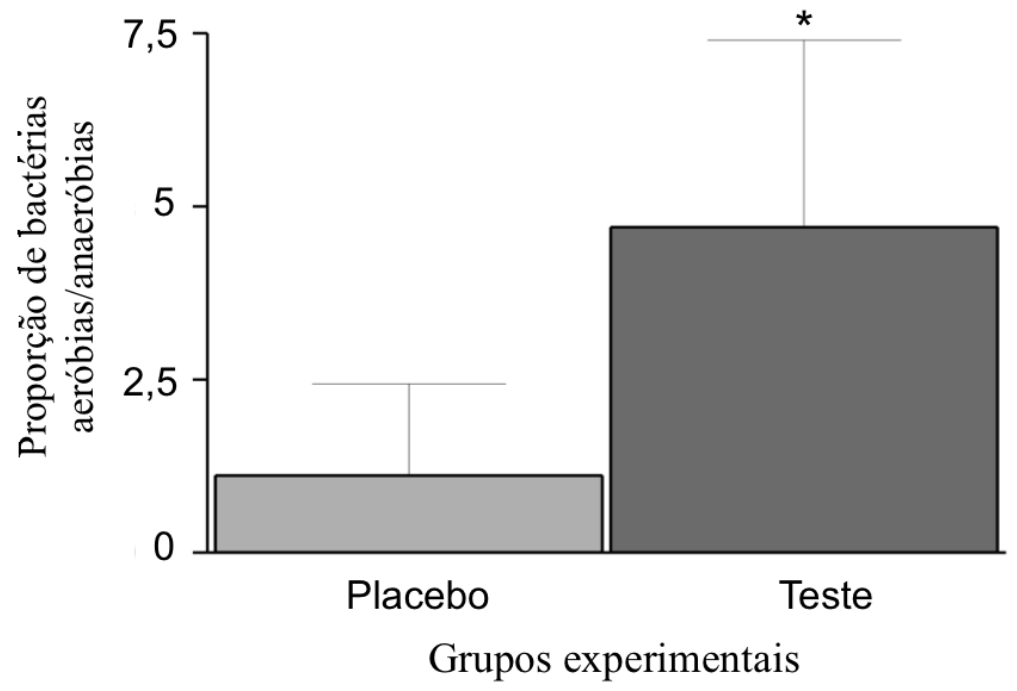

Figura 10 - Efeitos de B. lactis HN019 na microbiota associada às ligaduras durante o desenvolvimento da periodontite experimental. Médias e desvios padrão da razão entre bactérias aeróbias e anaeróbias nos grupos Teste e Placebo. $*=$ Diferença significativa $(p<0,05)$ quando comparado ao Grupo Placebo.

\subsection{Validação da RAR como tratamento da PE}

Os molares submetidos à indução da DP por meio da colocação de ligaduras e não tratados com RAR apresentaram ASOA significativamente maior que aquela de molares tratados com RAR aos 15 dias $\left(1,18 \mathrm{~mm}^{2} \pm 0.03\right.$ e $0,77 \mathrm{~mm}^{2} \pm 0.17$ respectivamente; Teste t pareado, $p<0,05)$. 
Díscussão 
A possibilidade de tratamento de doenças bucais com métodos naturais, não invasivos e não estressantes é particularmente atraente e pode prevenir problemas relacionados a tratamentos farmacológicos, como aqueles decorrentes do uso de antibióticos (40). Neste estudo, a terapia probiótica promoveu benefícios adicionais à RAR no tratamento da PE em ratos. A terapia probiótica influenciou o equilíbrio de citocinas pró-inflamatórias (IL-1 $\beta$ e CINC) e anti-inflamatórias (IL-10 e TGF- $\beta 1$ ), reduziu o número de osteoclastos, atenuou as perdas de inserção e de osso alveolar, controlou a inflamação local e favoreceu o reparo tecidual.

Este é o primeiro estudo que investiga os efeitos de microrganismos do gênero Bifidobacterium como adjuvante à RAR no tratamento da periodontite. Bactérias do gênero Bifidobacterium possuem diversos habitats, como o intestino humano, a cavidade bucal e o trato gastrointestinal animal (41). Esses microrganismos fazem parte da microbiota humana e possuem uma relação simbiótica com o hospedeiro, sendo capazes de inibir o crescimento de Candida albicans, Escherichia coli e outras bactérias patogênicas (24). B. lactis HN019, originado de lácteos, é considerado um probiótico em potencial e tem a capacidade de resistir à ação da bile e a pH bem ácidos (23). Essa estirpe também é capaz de aderir-se em quantidade elevada em diferentes tipos de células do epitélio intestinal (42) e apresenta propriedades imunomoduladoras (25). Estudos desenvolvidos em humanos mostraram que B. lactis HN019 foi capaz de melhorar a resposta imune inata de indivíduos idosos e de meia-idade (43), proporcionou um aumento na atividade citotóxica das células "Natural Killer" e na atividade fagocítica dos monócitos periféricos (44), diminuiu a deficiência em ferro em crianças pré-escolares (45) e promoveu a proteção dos enterócitos frente a uma infecção aguda (46). Shu et al. (47) demonstraram que $80 \%$ dos ratos tratados com B. lactis HN019 diariamente durante uma semana permaneceram vivos por três semanas após serem infectados com Salmonella typhimurium. Nos animais que não consumiram o probiótico, a taxa de mortalidade foi de 93\% (47).

No presente estudo, a escolha do uso de bactérias do gênero Bifidobacterium como potencial terapia adjuvante à RAR no tratamento da periodontite foi suportada por alguns estudos prévios que demonstraram os efeitos desses microrganismos no ambiente bucal. De acordo com esses estudos, B. lactis pode reduzir a quantidade de biofilme bacteriano nas superfícies dentárias e a inflamação gengival em indivíduos jovens saudáveis (28), bem como a quantidade de microrganismos associados à cárie dentária em crianças (27) e adultos jovens (48). Outros estudos in vitro (49-51) 
demonstraram que algumas espécies de Bifidobacterium possuem a capacidade de coagregação com Fusobacterium nucleatum, um tipo de microrganismo que atua como uma verdadeira "ponte biológica" na formação de biofilmes bucais, uma vez que se adere a quase todas as bactérias bucais (52). A capacidade de co-agregação é fundamental para que microrganismos probióticos possam integrar-se em comunidades microbianas bucais e também impedir a colonização de outras bactérias patogênicas. Jäsberg et al. (53) avaliaram a integração do probiótico Bifidobacterium animalis subsp. Lactis Bb12 e de isolados de Bifidobacterium dentium e Bifidobacterium longum em modelos in vitro de biofilme. Todas as bactérias integraram-se bem aos biofilmes subgengivais compostos por Porphyromonas gingivalis, Actinomyces naeslundii e Fusobacterium nucleatum.

No presente estudo, o biofilme subgingival dos animais não tratados (Grupos $\mathrm{C}$ e PROB) ou tratados com RAR (Grupos PE-RAR e PE-RAR-PROB) não foram avaliados devido às limitações inerentes ao modelo experimental. Sem a presença de ligaduras em ratos Wistar, é difícil coletar uma quantidade adequada de biofilme oral para análises microbiológicas apropriadas. Portanto, foi conduzido um experimento paralelo para avaliar os efeitos do B. lactis HN019 sobre a microbiota associada à ligadura durante o desenvolvimento de PE em ratos. Observou-se que este agente probiótico modulou a microbiota oral de uma forma que favoreceu o crescimento de bactérias aeróbias ao invés de bactérias anaeróbias. Como as bactérias associadas à periodontite são predominantemente anaeróbicas (54), esse achado sugere que o tratamento com B. lactis HN019 pode inibir a periodontite, pelo menos em parte, através da modulação da microbiota periodontal. Em um estudo recente, Oliveira et al. (33) demonstraram que as amostras de biofilme coletadas de ratos com DP induzida por ligadura e tratados com espécies de Bifidobacterium apresentaram maiores proporções de espécies semelhantes a Actinomyces e Streptococcus (espécies compatíveis com saúde periodontal), bem como menores proporções de espécies semelhantes à Veillonella parvula, Capnocytophaga sputigena, Eikenella corrodens e Prevotella intermedia (espécies envolvidas na patogênese da periodontite) quando comparadas àquelas de ratos não tratados com Bifidobacterium.

É importante considerar que a co-agregação de microrganismos probióticos com patógenos bucais livres pode ser maior do que aquela sobre patógenos integrados em um biofilme já estabelecido (55). Assim sendo, a remoção do biofilme bucal existente pode ser necessária antes da administração de um probiótico (17) a fim de potencializar 
seus efeitos antimicrobianos e capacidade de colonização. Portanto, no presente estudo, a terapia probiótica foi iniciada somente após a remoção do biofilme dos animais do Grupo PE-RAR-PROB por meio de RAR. Os resultados obtidos neste estudo para validação da RAR como tratamento da PE em ratos demonstraram que, após a indução da DP com a colocação de ligaduras e remoção das mesmas, os $1^{\text {os }}$ molares inferiores submetidos à RAR apresentaram menor ASOA que aqueles não submetidos a essa terapia mecânica aos 15 dias pós-operatórios.

No que se refere à modulação da resposta imunoinflamatória do hospedeiro nos tecidos periodontais, ainda há uma grande lacuna na literatura sobre os reais mecanismos de ação dos probióticos. Desde que mecanismos imunoinflamatórios similares, determinantes no processo de saúde-doença do hospedeiro, ocorrem nos tecidos periodontais e na mucosa intestinal, acredita-se que a ação imunoinflamatória de probióticos na cavidade bucal seja análoga àquela descrita na mucosa intestinal. Neste estudo, uma expressão mais baixa de IL-1 $\beta$ e uma maior expressão de IL-10 foram observadas no grupo PE-RAR-PROB quando comparado ao grupo PE-RAR. Níveis mais elevados de IL-10 foram também observados no cólon de camundongos gnotobióticos desafiados com Salmonella typhimurium e tratados com B. lactis (56). A IL-10 exerce efeitos inibitórios sobre IL-1 $\beta$ e no fator de necrose tumoral alfa, os quais apresentam ações sinérgicas nos processos inflamatórios, amplificando a resposta do hospedeiro (57). A relação elevada IL-1 / IL-10 no fluido crevicular gengival pode estar relacionada à progressão da periodontite agressiva (58).

A terapia probiótica como adjuvante à RAR também reduziu a magnitude da resposta inflamatória e melhorou a reparação tecidual no grupo PE-RAR-PROB, aumentando a expressão de TGF- $\beta 1$ nos tecidos periodontais. Estudos anteriores já demonstraram que $B$. lactis HN019 pode aumentar os níveis de TGF- $\beta 1$ no leite materno (59) e no sangue (60). O TGF- $\beta$ suprime a produção de colagenase por fibroblastos e macrófagos, aumenta a expressão de inibidores teciduais de metaloproteinases da matriz, aumenta a síntese de moléculas de matriz extracelular e promove efeitos químico-atraentes em células ósseas.

Um número reduzido de células multinucleadas TRAP-positivas foi encontrado no grupo PE-RAR-PROB quando comparado ao grupo PE-RAR. Isto pode ser explicado, em parte, pela expressão reduzida de CINC (homólogo da IL-8 humana) nos tecidos periodontais dos animais tratados com probiótico. Liu et at. (46) demonstraram que $B$. lactis HN019 exerce efeitos anti-inflamatórios no epitélio através da regulação 
negativa da secreção de IL-8. A IL-8 está envolvida em uma grande variedade de doenças e é uma importante citocina pró-inflamatória e fator imunomodulador, podendo induzir a diferenciação/maturação dos osteoclastos e manter a atividade de reabsorção óssea envolvida na destruição do tecido periodontal (61).

O grupo PROB apresentou maior PC e AV em amostras de duodeno, jejuno e íleo quando comparado com os demais grupos. Além disso, o grupo PE-RAR-PROB apresentou maior PC do que o grupo PE-RAR em amostras de duodeno e jejuno. De fato, os probióticos podem melhorar a função da barreira da mucosa do hospedeiro, promovendo uma diminuição da reatividade imunológica, deslocando micróbios deletérios da superfície da mucosa e modulando o sistema imune local (62). Em um estudo prévio do nosso grupo (38), foi demonstrado que a suplementação probiótica protege o intestino delgado de alterações reativas induzidas pela PE. É importante pontuar que uma diminuição da inflamação intestinal pode estar relacionada a uma melhoria da saúde periodontal. Grossner-Schreiber et at. (63) relataram um aumento da prevalência de DP em pacientes com doença inflamatória intestinal.

O presente estudo demonstrou que o probiótico B. lactis HN019 apresenta potencial terapêutico para o tratamento da periodontite. Novos estudos são fundamentais para confirmar esses achados em modelos experimentais animais de escala filogenética superior e, também, em ensaios clínicos controlados. Além disso, são necessárias investigações mais aprofundadas da possível influência de diversos fatores nos resultados obtidos, tais como: dose diária, frequência de administração diária, período de administração (antes, durante ou após as refeições), duração da administração (de um dia a vários meses), veículo usado para a liberação do probiótico (comida fermentada, bebida, cápsula, comprimido ou pó), viabilidade da cepa probiótica e potencial de colonização da mesma no ambiente bucal. 
conclusão 
Dentro dos limites deste estudo, pode-se concluir que a utilização de B. lactis HN019 como adjuvante à RAR promove benefícios histológicos, microtomográficos e imunológicos adicionais no tratamento da PE em ratos, bem como melhora a morfologia intestinal dos animais. 
Referências 
1. Eke PI, Dye BA, Wei L, Thornton-Evans GO, Genco RJ, Cdc Periodontal Disease Surveillance workgroup: James Beck GDRP. Prevalence of periodontitis in adults in the United States: 2009 and 2010. Journal of dental research. 2012;91(10):91420

2. Haffajee AD, Socransky SS. Microbial etiological agents of destructive periodontal diseases. Periodontology 2000. 1994;5:78-111.

3. Grossi SG, Zambon JJ, Ho AW, Koch G, Dunford RG, Machtei EE, et al. Assessment of risk for periodontal disease. I. Risk indicators for attachment loss. Journal of periodontology. 1994;65(3):260-7.

4. Salvi GE, Lang NP. Host response modulation in the management of periodontal diseases. Journal of clinical periodontology. 2005;32 Suppl 6:108-29.

5. Berezow AB, Darveau RP. Microbial shift and periodontitis. Periodontology 2000. 2011;55(1):36-47.

6. Assuma R, Oates T, Cochran D, Amar S, Graves DT. IL-1 and TNF antagonists inhibit the inflammatory response and bone loss in experimental periodontitis. Journal of immunology. 1998;160(1):403-9.

7. Greenstein G. Local drug delivery in the treatment of periodontal diseases: assessing the clinical significance of the results. Journal of periodontology. 2006;77(4):565-78.

8. Quirynen M, Avontroodt P, Peeters W, Pauwels M, Coucke W, van Steenberghe D. Effect of different chlorhexidine formulations in mouthrinses on de novo plaque formation. Journal of clinical periodontology. 2001;28(12):1127-36.

9. Foligne B, Daniel C, Pot B. Probiotics from research to market: the possibilities, risks and challenges. Current opinion in microbiology. 2013;16(3):284-92.

10. McFarland LV. From yaks to yogurt: the history, development, and current use of probiotics. Clinical infectious diseases : an official publication of the Infectious Diseases Society of America. 2015;60 Suppl 2:S85-90.

11. Ouwehand A, Vesterlund S. Health aspects of probiotics. IDrugs : the investigational drugs journal. 2003;6(6):573-80.

12. Amrouche T, Boutin Y, Moroni O, Kheadr E, Fliss I. Production and characterization of anti-bifidobacteria monoclonal antibodies and their application in the development of an immuno-culture detection method. Journal of microbiological methods. 2006;65(1):159-70. 
13. Commane D, Hughes R, Shortt C, Rowland I. The potential mechanisms involved in the anti-carcinogenic action of probiotics. Mutation research. 2005;591(12):276-89.

14. Teughels W, Van Essche M, Sliepen I, Quirynen M. Probiotics and oral healthcare. Periodontology 2000. 2008;48:111-47.

15. Martin-Cabezas R, Davideau JL, Tenenbaum H, Huck O. Clinical efficacy of probiotics as an adjunctive therapy to non-surgical periodontal treatment of chronic periodontitis: a systematic review and meta-analysis. Journal of clinical periodontology. 2016;43(6):520-30.

16. Gruner D, Paris S, Schwendicke F. Probiotics for managing caries and periodontitis: Systematic review and meta-analysis. Journal of dentistry. 2016;48:16-25.

17. Teughels W, Durukan A, Ozcelik O, Pauwels M, Quirynen M, Haytac MC. Clinical and microbiological effects of Lactobacillus reuteri probiotics in the treatment of chronic periodontitis: a randomized placebo-controlled study. Journal of clinical periodontology. 2013;40(11):1025-35.

18. Vivekananda MR, Vandana KL, Bhat KG. Effect of the probiotic Lactobacilli reuteri (Prodentis) in the management of periodontal disease: a preliminary randomized clinical trial. Journal of oral microbiology. 2010;2.

19. Shah MP, Gujjari SK, Chandrasekhar VS. Evaluation of the effect of probiotic (inersan $(\mathrm{R})$ ) alone, combination of probiotic with doxycycline and doxycycline alone on aggressive periodontitis - a clinical and microbiological study. Journal of clinical and diagnostic research : JCDR. 2013;7(3):595-600.

20. Ince G, Gursoy H, Ipci SD, Cakar G, Emekli-Alturfan E, Yilmaz S. Clinical and Biochemical Evaluation of Lozenges Containing Lactobacillus reuteri as an Adjunct to Non-Surgical Periodontal Therapy in Chronic Periodontitis. Journal of periodontology. 2015;86(6):746-54.

21. Tekce M, Ince G, Gursoy H, Dirikan Ipci S, Cakar G, Kadir T, et al. Clinical and microbiological effects of probiotic lozenges in the treatment of chronic periodontitis: a 1-year follow-up study. Journal of clinical periodontology. 2015;42(4):363-72.

22. Teughels W, Loozen G, Quirynen M. Do probiotics offer opportunities to manipulate the periodontal oral microbiota? Journal of clinical periodontology. 2011;38 Suppl 11:159-77. 
23. Prasad J, Gill H, Smart J, Gopal PK. Selection and Characterisation of Lactobacillus and Bifidobacterium Strains for Use as Probiotics. International Dairy Journal. 1998;8(12):993-1002.

24. Biavati B, Vescovo M, Torriani S, Bottazzi V. Biifidobacteria: history, ecology, physiology and applications. Ann. Microbiol. 2000;50:117-131.

25. Gill HS, Rutherfurd KJ, Prasad J, Gopal PK. Enhancement of natural and acquired immunity by Lactobacillus rhamnosus (HN001), Lactobacillus acidophilus (HN017) and Bifidobacterium lactis (HN019). The British journal of nutrition. 2000;83(2):167-76.

26. Caglar E, Kuscu OO, Selvi Kuvvetli S, Kavaloglu Cildir S, Sandalli N, Twetman S. Short-term effect of ice-cream containing Bifidobacterium lactis Bb-12 on the number of salivary mutans streptococci and lactobacilli. Acta odontologica Scandinavica. 2008;66(3):154-8.

27. Singh RP, Damle SG, Chawla A. Salivary mutans streptococci and lactobacilli modulations in young children on consumption of probiotic ice-cream containing Bifidobacterium lactis Bb12 and Lactobacillus acidophilus La5. Acta odontologica Scandinavica. 2011;69(6):389-94.

28. Toiviainen A, Jalasvuori H, Lahti E, Gursoy U, Salminen S, Fontana M, et al. Impact of orally administered lozenges with Lactobacillus rhamnosus GG and Bifidobacterium animalis subsp. lactis $\mathrm{BB}-12$ on the number of salivary mutans streptococci, amount of plaque, gingival inflammation and the oral microbiome in healthy adults. Clinical oral investigations. 2015;19(1):77-83.

29. Rotimi VO, Duerden BI. The development of the bacterial flora in normal neonates. Journal of medical microbiology. 1981;14(1):51-62.

30. Gueimonde M, Laitinen K, Salminen S, Isolauri E. Breast milk: a source of bifidobacteria for infant gut development and maturation? Neonatology. 2007;92(1):646.

31. Abrahamsson TR, Sinkiewicz G, Jakobsson T, Fredrikson M, Bjorksten B. Probiotic lactobacilli in breast milk and infant stool in relation to oral intake during the first year of life. Journal of pediatric gastroenterology and nutrition. 2009;49(3):349-54. 32. Hojo K, Mizoguchi C, Taketomo N, Ohshima T, Gomi K, Arai T, et al. Distribution of salivary Lactobacillus and Bifidobacterium species in periodontal health and disease. Bioscience, biotechnology, and biochemistry. 2007;71(1):152-7. 
33. Oliveira LF, Salvador SL, Silva PH, Furlaneto FA, Figueiredo L, Casarin R, et al. Benefits of Bifidobacterium Animalis Subsp Lactis Probiotic in Experimental Periodontitis. Journal of periodontology. 2016:1-20.

34. Bosch M, Nart J, Audivert S, Bonachera MA, Alemany AS, Fuentes MC, et al. Isolation and characterization of probiotic strains for improving oral health. Archives of oral biology. 2012;57(5):539-49.

35. Hoffman FA, Heimbach JT, Sanders ME, Hibberd PL. Executive summary: scientific and regulatory challenges of development of probiotics as foods and drugs. Clinical infectious diseases : an official publication of the Infectious Diseases Society of America. 2008;46 Suppl 2:S53-7.

36. Garcia VG, Longo M, Fernandes LA, Gualberto EC, Jr., Santinoni Cdos S, Bosco AF, et al. Treatment of experimental periodontitis in rats using repeated adjunctive antimicrobial photodynamic therapy. Lasers in medical science. 2013;28(1):143-50.

37. Lisboa MR, Gondim DV, Ervolino E, Vale ML, Frota NP, Nunes NL, et al. Effects of electroacupuncture on experimental periodontitis in rats. Journal of periodontology. 2015;86(6):801-11.

38. Messora MR, Oliveira LF, Foureaux RC, Taba M, Jr., Zangeronimo MG, Furlaneto FA, et al. Probiotic therapy reduces periodontal tissue destruction and improves the intestinal morphology in rats with ligature-induced periodontitis. Journal of periodontology. 2013;84(12):1818-26.

39. Maekawa T, Hajishengallis G. Topical treatment with probiotic Lactobacillus brevis CD2 inhibits experimental periodontal inflammation and bone loss. Journal of periodontal research. 2014;49(6):785-91.

40. Nissen L, Sgorbati B, Biavati B, Belibasakis GN. Lactobacillus salivarius and L. gasseri down-regulate Aggregatibacter actinomycetemcomitans exotoxins expression. Annals of microbiology. 2014;64:611-7.

41. Dong X, Cheng G, Jian W. Simultaneous identification of five bifidobacterium species isolated from human beings using multiple PCR primers. Systematic and applied microbiology. 2000;23(3):386-90.

42. Gopal PK, Prasad J, Smart J, Gill HS. In vitro adherence properties of Lactobacillus rhamnosus DR20 and Bifidobacterium lactis DR10 strains and their antagonistic activity against an enterotoxigenic Escherichia coli. International journal of food microbiology. 2001;67(3):207-16. 
43. Gill HS, Rutherfurd KJ, Cross ML. Dietary probiotic supplementation enhances natural killer cell activity in the elderly: an investigation of age-related immunological changes. Journal of clinical immunology. 2001;21(4):264-71.

44. Zhou JS, Gill HS. Immunostimulatory probiotic Lactobacillus rhamnosus HN001 and Bifidobacterium lactis HN019 do not induce pathological inflammation in mouse model of experimental autoimmune thyroiditis. International journal of food microbiology. 2005;103(1):97-104.

45. Sazawal S, Dhingra U, Hiremath G, Sarkar A, Dhingra P, Dutta A, et al. Effects of Bifidobacterium lactis HN019 and prebiotic oligosaccharide added to milk on iron status, anemia, and growth among children 1 to 4 years old. Journal of pediatric gastroenterology and nutrition. 2010;51(3):341-6.

46. Liu C, Zhang ZY, Dong K, Guo XK. Adhesion and immunomodulatory effects of Bifidobacterium lactis HN019 on intestinal epithelial cells INT-407. World journal of gastroenterology. 2010;16(18):2283-90.

47. Shu Q, Lin H, Rutherfurd KJ, Fenwick SG, Prasad J, Gopal PK, et al. Dietary Bifidobacterium lactis (HN019) enhances resistance to oral Salmonella typhimurium infection in mice. Microbiology and immunology. 2000;44(4):213-22.

48. Caglar E, Kuscu OO, Cildir SK, Kuvvetli SS, Sandalli N. A probiotic lozenge administered medical device and its effect on salivary mutans streptococci and lactobacilli. International journal of paediatric dentistry. 2008;18(1):35-9.

49. Stamatova I, Kari K, Vladimirov S, Meurman JH. In vitro evaluation of antimicrobial activity of putative probiotic lactobacilli against oral pathogens. Int $\mathrm{J}$ Probiotics. 2008;2:225-32.

50. Nagaoka S, Hojo K, Murata S, Mori T, Ohshima T, Maeda N. Interactions between salivary Bifidobacterium adolescentis and other oral bacteria: in vitro coaggregation and coadhesion assays. FEMS microbiology letters. 2008;281(2):183-9.

51. Ledder RG, Timperley AS, Friswell MK, Macfarlane S, McBain AJ. Coaggregation between and among human intestinal and oral bacteria. FEMS microbiology ecology. 2008;66(3):630-6.

52. Rickard AH, Gilbert P, High NJ, Kolenbrander PE, Handley PS. Bacterial coaggregation: an integral process in the development of multi-species biofilms. Trends in microbiology. 2003;11(2):94-100. 
53. Jasberg H, Soderling E, Endo A, Beighton D, Haukioja A. Bifidobacteria inhibit the growth of Porphyromonas gingivalis but not of Streptococcus mutans in an in vitro biofilm model. European journal of oral sciences. 2016;124(3):251-8.

54. Darveau RP. Periodontitis: a polymicrobial disruption of host homeostasis. Nature reviews Microbiology. 2010;8(7):481-90.

55. Marttinen AM, Haukioja AL, Keskin M, Soderling EM. Effects of Lactobacillus reuteri PTA 5289 and L. paracasei DSMZ16671 on the adhesion and biofilm formation of Streptococcus mutans. Current microbiology. 2013;67(2):193-9.

56. Martins AK, Martins FS, Gomes DA, Elian SD, Vieira AT, Teixeira MM, et al. Evaluation of in vitro antagonism and of in vivo immune modulation and protection against pathogenic experimental challenge of two probiotic strains of Bifidobacterium animalis var. lactis. Archives of microbiology. 2010;192(12):995-1003.

57. Moore KW, de Waal Malefyt R, Coffman RL, O'Garra A. Interleukin-10 and the interleukin-10 receptor. Annual review of immunology. 2001;19:683-765.

58. Teles RP, Gursky LC, Faveri M, Rosa EA, Teles FR, Feres M, et al. Relationships between subgingival microbiota and GCF biomarkers in generalized aggressive periodontitis. Journal of clinical periodontology. 2010;37(4):313-23.

59. Prescott SL, Wickens K, Westcott L, Jung W, Currie H, Black PN, et al. Supplementation with Lactobacillus rhamnosus or Bifidobacterium lactis probiotics in pregnancy increases cord blood interferon-gamma and breast milk transforming growth factor-beta and immunoglobin A detection. Clinical and experimental allergy : journal of the British Society for Allergy and Clinical Immunology. 2008;38(10):1606-14.

60. Ouwehand AC, Bergsma N, Parhiala R, Lahtinen S, Gueimonde M, FinneSoveri $\mathrm{H}$, et al. Bifidobacterium microbiota and parameters of immune function in elderly subjects. FEMS immunology and medical microbiology. 2008;53(1):18-25.

61. Zhang Y, Li X. Lipopolysaccharide-regulated production of bone sialoprotein and interleukin-8 in human periodontal ligament fibroblasts: the role of toll-like receptors 2 and 4 and the MAPK pathway. Journal of periodontal research. 2015;50(2):141-51.

62. Vanderpool C, Yan F, Polk DB. Mechanisms of probiotic action: Implications for therapeutic applications in inflammatory bowel diseases. Inflammatory bowel diseases. 2008;14(11):1585-96. 
63. Grössner-Schreiber B, Fetter T, Hedderich J, Kocher T, Schreiber S, Jepsen S. Prevalence of dental caries and periodontal disease in patients with inflammatory bowel disease: a case-control study. Journal of clinical periodontology. 2006;33(7):478-84. 
Anexo 


\title{
ANEXO A - CERTIFICADO DA COMISSÃO DE ÉTICA NO USO DE
}

\section{ANIMAIS}

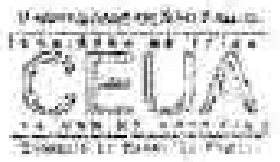

\author{
UNIVERSIDADE DE SÃO PAULO \\ Campus de Ribeirão Preto \\ Comissão de Ética no Uso de Animais \\ C E R T I F I C A D O
}

Certificamos que o trabalho (Protocolo 13.1.136.53.5), intitulado "Influéncia da Terapia Probiótica como Adjuvante no Tratamento não cirúrgico da Periodontite. Estudo histornorfonetrico em ratos". de autoria de Gustavo Carvalho Teixeira e Michel Reis Messora, for estar de acordo com os Principios Éticos na Experimentaçào Animal adotado pela Comissăo de Ética no Uso de Animais (CEUA) do Campus de Ribeirão Preto - USP, foi aprovado em reunião da CEUA de 06/05/2013.

This is to certify that the work (Protocol number 13.1.136 53.5), entitled: "Influência da Terapia Probiótica como Adjuvante no Tratamento näo cirúrgico da Periodontite. Estudo histomorfométrico em ratos", by Gustavo Carvalho Teixeira and Michel Reis Messora is in accordance with the Ethic Principies in Animal Experimentation adopted by Ethic Commission for the Use of Animais (CEUA) of the Campus of Ribeirão Preto - USP, and was approved in an ordinary meeting of CEUA, May, 62013.

Ribeirăo Preto, 13 de Junho de 2014.

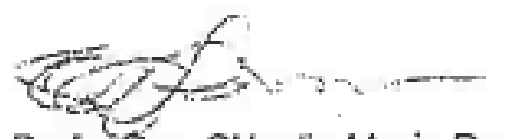

Profa. Dra. Clęudia Naria Padovan

Presidente da CEUA

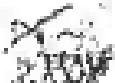

Joâo Fénando Veiho de Andrade Diniz

Secretărio da CEUA 
ANEXO B - Artigo científico submetido para publicação no periódico PLOS ONE

EFFECTS of the PROBIOTIC Bifidobacterium animalis subsp. lactis on the NON-SURGICAL TREATMENT OF PERIODONTITIS. A HISTOMORPHOMETRIC, MICROTOMOGRAPHIC and IMMUNOHISTOCHEMICAL STUDY in RATS.

Short title: Bifidobacterium probiotics on experimental periodontitis nas normas, parei em: Materials and Methods

Milla S. T. Ricoldi ; Flávia A. C. Furlaneto, DDS, $\mathrm{PhD}^{1}$; Luiz F. F. Oliveira, DDS ${ }^{1}$; Gustavo C. Teixeira, DDS ${ }^{1}$, Jéssica P. Pischiotini, DDS ${ }^{1}$; André L. G. Moreira, DDS, $\mathrm{MS}^{2}$; Edilson Ervolino, DDS, $\mathrm{PhD}^{3}$; Maricê N. de Oliveira, Pharm.D., $\mathrm{PhD}^{4}$; Cristina; S. B. Bogsan, Pharm.D., $\mathrm{PhD}^{4}$; Sérgio L. Salvador, Pharm.D, $\mathrm{PhD}^{5}$;; Michel R. Messora, DDS, $\mathrm{PhD}^{1 *}$

${ }^{1}$ Department of Oral and Maxillofacial Surgery and Periodontology, School of Dentistry of Ribeirao Preto, University of Sao Paulo - USP, Ribeirao Preto/ SP, Brazil.

${ }^{2}$ Private Practice, Salvador/ BA, Brazil.

${ }^{3}$ Department of Basic Sciences, Division of Histology, Dental School of Aracatuba, UNESP-Univ Estadual Paulista, Aracatuba/ SP, Brazil.

${ }^{4}$ Department of Biochemical and Pharmaceutical Technology, School of Pharmaceutical Sciences, University of Sao Paulo - USP, Sao Paulo/ SP, Brazil.

${ }^{5}$ Department of Clinical Analyses, School of Pharmaceutical Sciences of Ribeirao Preto, University of São Paulo - USP, Ribeirão Preto/ SP, Brazil.

*Corresponding author: 
Michel R. Messora

E-mail address: m.messora@forp.usp.br (MRM)

\section{Abstract}

Lactobacillus probiotics have been investigated in periodontitis. However, the effects of the genus Bifidobacterium on periodontitis are hardly known. This study evaluated the effects of the probiotic Bifidobacterium animalis subsp. lactis (B. lactis) HN019 as an adjunct to scaling and root planing (SRP) in rats with experimental periodontitis (EP). At baseline, 32 rats were assigned to 4 groups: C (control), PROB, EP-SRP and EP-SRP-PROB. In groups EP-SRP and EP-SRP-PROB, the mandibular first molars of the animals received a ligature. At day 14, the ligatures were removed and SRP was performed. Animals of groups PROB and EP-SRP-PROB were orally administered with $10 \mathrm{~mL} /$ day of $10^{9}$ colony forming units of B. lactis HN019 for 15 days, starting at day 14. Animals were euthanized at day 29. Histomorphometric, microtomographic and immunohistochemical analyses were performed. Microbiological effects of B. lactis on biofilm were also evaluated. Data were statistically analyzed. Group EP-SRP-PROB presented reduced alveolar bone resorption and attachment loss when compared with Group EP-SRP $(p<0.05)$. Group EP-SRP-PROB showed significantly fewer osteoclasts, increased expression of anti-inflammatory cytokines and reduced expression of proinflammatory cytokines compared with Group EP-SRP $(p<0.05)$. B. lactis promoted a higher ratio between aerobic and anaerobic bacteria in biofilm samples $(p<0.05)$. The use of $B$. lactis HN019 potentiates the effects of SRP in the treatment of EP in rats. 


\section{Introduction}

The development of novel and effective therapeutic strategies as adjuncts to clinical periodontal treatment are required [1]. The use of beneficial bacteria has arisen as a potential concept in the prevention and treatment of periodontal diseases [2]. According to the World Health Organization, probiotics are live microorganisms that can confer health benefits to the host when consumed in adequate amounts [3]. The mechanisms of action of probiotics are poorly understood although they appear to involve host immunomodulation and remodeling of the structure and function of microbial communities $[1,4]$.

The studies that evaluated the effects of probiotics on the treatment of periodontal disease demonstrated that they can reduce periodontopathogens, improve periodontal clinical parameters, decrease the levels of pro-inflammatory cytokines and potentiate the effects of scaling and root planing (SRP) [2,5-8].

Although the scientific literature presents promising results, it is important to consider that the findings obtained with probiotics can not be generalized [9] once they are dependent on the strain, dosage, frequency and route of administration used. The studies that investigated the effects of probiotics on periodontal diseases to date used mainly microorganisms from the genus Lactobacillus. However, other potential probiotics deserve investigations. Bifidobacterium animalis subsp. lactis (B. lactis) composes the human microbiota and presents a symbiotic relationship with the host. It is considered a potential probiotic because possesses immunomodulatory [10-12] and antimicrobial [13-15] properties. 
Validated preclinical methods studies, such as the use of animal models of periodontitis, may provide important new data about the safety and efficacy of probiotics [16]. Recently, our group evaluated the topical use of one strain of B. lactis, named HN019, on the development of experimental periodontitis (EP) in rats. It was observed that the treatment promoted a protective effect against periodontal breakdown, modifying immunoinflammatory and microbiological parameters [17]. To the best of our knowledge, there are no studies evaluating the effects of B. lactis HN019 associated with SRP on periodontitis. Therefore, the purpose of this study was to evaluate the histomorphometric, microtomographic and immunohistochemical outcomes following the administration of B. lactis HN019 as an adjunct to SRP in rats with ligature-induced periodontitis. Microbiological effects of B. lactis HN019 on biofilm during the development of EP were also evaluated.

\section{Materials and Methods}

\section{Sample}

This study was conducted after review and approval by the Ethics Committee on Animal Experimentation at School of Dentistry of Ribeirao Preto, University of Sao Paulo - FORP/USP (protocol 13.1.136.53.5). Authors followed the ARRIVE (Animal Research: Reporting of In Vivo Experiments) guidelines.

The sample size was determined to provide $80 \%$ power to recognize a significant difference of $20 \%$ among groups and the standard deviation of $15 \%$ with a 95\% confidence interval $(\alpha=0.05)$, considering the change in the alveolar bone in the furcation area (Area of No Bone - ANB) as the primary outcome variable. Therefore, a sample size of eight animals per group was required. 


\section{Experimental model}

Thirty-two adult male Wistar rats (Rattus norvegicus, albinus), weighing 230$250 \mathrm{~g}$, were used (Central Animal Facility, FORP/USP). The rats were kept in a 12-hour light/dark cycle and temperatures between 22 and $24^{\circ} \mathrm{C}$. They were housed in individual metabolic cages and fed with selected solid diet and water ad libitum. Rats were assigned to the following groups ( $\mathrm{n}=8)$ : Group C (control); Group PROB (probiotic); Group EP-SRP (experimental periodontitis + scaling and root planing) and Group EPSRP-PROB (experimental periodontitis + scaling and root planing + probiotic). All analyses were performed by calibrated and blinded examiners.

\section{Induction of EP}

In Groups EP-SRP and EP-SRP-PROB, animals were anesthetized by an intraperitoneal injection of xylazine (Rompum $^{\circledR}$, Bayer Animal Health, Sao Paulo, SP, Brazil; $10 \mathrm{mg} / \mathrm{kg}$ body weight) and ketamine (Dopalen ${ }^{\circledR}$, Agribands Purina do Brasil Ltda., Paulinia, SP, Brazil; $80 \mathrm{mg} / \mathrm{kg}$ body weight). A cotton ligature was placed around their right mandibular first molars, as previously described [18].

\section{SRP procedures}

After 14 days, the animals were anesthetized, as previously described, and the ligatures (groups EP-SRP and EP-SRP-PROB) were removed. The right mandibular first molars of the animals of these groups were subjected to SRP with manual Mini Five 1-2 curettes (Hu-Friedy Co. Inc., Chicago, IL, USA) through ten distal-mesial traction movements in both buccal and lingual aspects. The furcation and interproximal areas were scaled with the same curettes through cervico-occlusal traction movements. 


\section{Probiotic therapy}

Starting from day 14 of the experiment, $10 \%$ skimmed milk (Molico ${ }^{\circledR}$, Nestle Brasil Ltda., Sao Paulo, SP, Brazil) was orally administered to the animals once a day (at 8:00 am) during 15 days. For Groups PROB and EP-SRP-PROB, 10\% skimmed milk were inoculated with B. lactis HN019 (Howaru Bifidus Lyo 40 DCU, DuPont ${ }^{\mathrm{TM}}$ Danisco ${ }^{\circledR} /$ Fermentech, Sao Paulo, SP, Brazil) culture to obtain $10^{9}$ colony-forming units $(\mathrm{CFU}) / 10 \mathrm{~mL}$. In Group EP-SRP-PROB, probiotic therapy was initiated immediately after SRP. The animals of Groups C and EP-SRP received $10 \mathrm{~mL}$ of $10 \%$ skimmed milk with placebo (without B. lactis HN019).

\section{Euthanasia}

Animals were euthanized with a lethal dose $(150 \mathrm{mg} / \mathrm{kg}$ body weight $)$ of sodium thiopental (Thiopentax ${ }^{\circledR}$, Cristalia Produtos Quimicos Farmaceuticos Ltda., Sao Paulo, SP, Brazil) at day 29 of the experiment. The hemimandibles were excised and tissue samples from distinctive parts of the small intestines (duodenum, jejunum, ileum) were collected. All specimens were fixed in $4 \%$ formaldehyde for 24 hours.

\section{Microcomputed tomography (Micro-CT) analyses}

Non-demineralized specimens were scanned by a cone-beam micro-CT system (Skyscan 1172, Bruker, Kontich, Belgium). The x-ray generator was operated at an accelerated potential of $60 \mathrm{kV}$ with a beam current of $165 \mu \mathrm{A}$ and an exposure time of $650 \mathrm{~ms}$ per projection. Images were produced with a voxel size of $6 \times 6 \times 6 \mu \mathrm{m}$.

Using an appropriated software (Data Viewer ${ }^{\circledR}$, version 1.5.0, Bruker, Kontich, Belgium), the generated 3 dimensional models were rotated into a standard position as 
the following criteria: (1) in transaxial plane, the mandibular first molar (M1) had its axis vertically positioned, (2) in coronal plane, the mandibular bone was vertically orientated, with the mesial root of the M1 in the upper position of the image and (3) in sagittal plane, the occlusal surface of M1 was horizontally positioned. Linear measurements on alveolar bone level (ABL) were performed at four different sites: buccal, lingual, interproximal and furcation. For buccal, lingual and interproximal sites, the linear distances from cementoenamel junction (CEJ) to alveolar bone crest (ABC) were measured [19]. For the interproximal site, coronal dataset was analyzed using appropriated software (CT-Analyser ${ }^{\circledR}$, version 1.13.5.1+, Bruker, Kontich, Belgium). For the furcation site, ABL was assessed by measuring the distance between the roof of the furcation and the $\mathrm{ABC}$ in the furcation area. The four linear measurements obtained from each animal were summed to express the ABL value.

For volumetric measurements, a volume of interest (VOI-prismatic section) was outlined from the apexes of all roots of M1 up to the roof of the furcation of M1, touching the roots surfaces, in all images of the coronal dataset, using the software CTAnalyser $^{\circledR}$. The following parameters were analyzed: i) Bone Volume (BV): percentual of the VOI filled with bone tissue; ii) Mean Bone Porosity (BP): percentual of bone porosity present in the VOI.

\section{Histomorphometric analysis of periodontal tissues}

After routine laboratorial processing [18], two sections representing the most central buccal-lingual portion in the furcation area of right mandibular first molars were selected for histopathological and histometric analyses. The histopathological analysis was performed by a certified histologist (E.E.) using a light microscope.

For histometric analysis, photomicrographs were captured by a digital camera (DM2000, Leica Microsystems, Wetzlar, Germany) connected to a light microscope 
(DFC295, Leica Microsystems, Wetzlar, Germany). The images were analyzed using appropriate software (Diracon Bio Informatica Ltda., Vargem Grande do Sul, SP, Brazil). The ANB and the attachment loss (AL) were measured $[18,19]$.

\section{Immunohistochemical analyses of periodontal tissues}

Immunohistochemical processing was performed through the indirect immunoperoxidase method, as previously described [20]. The histological slides containing samples from all experimental groups were incubated with one of the following primary antibodies: rabbit anti-interleukin (IL)-1 $\beta$ (1:100-Rabbit anti-IL-1 $\beta$ SC 7884, Santa Cruz Biotechnology, Santa Cruz, CA, USA), goat anti-cytokineinduced neutrophil chemoattractant - CINC (1:100-Goat anti-CINC1-ab 10365, abcam $^{\circledR}$, Cambridge, MA, USA), goat anti-IL-10 (1:100-Goat anti-IL-10-SC 1783, Santa Cruz Biotechnology), rabbit anti-transforming growth factor (TGF)- $\beta 1$ (1:200Rabbit anti-TGF- $\beta 1-$ SC 146, Santa Cruz Biotechnology) or goat anti-tartrate-resistant acid phosphatase - TRAP (1:100-Goat anti-TRAP-SC 30833, Santa Cruz Biotechnology). Histologic sections were evaluated under light microscopy with an optical microscope (Axiovision 4.8.2, Carl Zeiss MicroImaging GmbH, Jena, Germany).

A quantitative immunolabeling analysis of TRAP-positive cells and semiquantitative immunolabeling analyses of IL-1 $\beta$, CINC, IL-10 and TGF- $\beta 1$ were conducted in the entire furcation region at 400x magnification [19]. For semiquantitative analyses, the following scores were determined: score 0-no immunolabeling (total absence of immunoreactivity in the area); score 1-low immunolabeling pattern $(\approx 1 / 3$ of the area presenting immunoreactivity); score $2-$ moderate immunolabeling pattern $(\approx 2 / 3$ of the area presenting immunoreactivity) and score 3-high immunolabeling pattern (almost the totality of the area presenting immunoreactivity). 


\section{Histomorphometric analysis of small intestine}

The collected samples were routinely processed [18]. For histometric analyses, the measurements included villous height (VH) and crypt depth (CD), as previously described [18].

\section{Effects of B. lactis HN019 on ligature-associated microbiota}

Twelve adult male Wistar rats (Rattus norvegicus, albinus), weighing 230-250g, not used in the experiments previously described, were used. Animals were divided into groups Placebo $(n=6)$ and Test $(n=6)$. A cotton ligature was placed around their right mandibular first molars, as described by Messora et al. (2013) [18]. 10\% skimmed milk $\left(\right.$ Molico $^{\circledR}$ ) was orally administered to the animals once a day during 15 days. In Group Test, the milk was inoculated with B. lactis HN019 (Howaru Bifidus Lyo 40 DCU) culture to obtain $10^{9} \mathrm{CFU} / 10 \mathrm{~mL}$.

The ligatures were recovered from the rats at day 15 and incubated under aerobic and anaerobic conditions for 7 days at $35^{\circ} \mathrm{C}$ for enumeration of total cultivable $\mathrm{CFU}$ [1]. The ratio between aerobic and anaerobic bacteria was calculated in each group.

\section{Statistical analyses}

Normality and homoscedasticity of the data were verified. The significance of differences among groups in relation to the immunolabeling pattern of IL- $1 \beta$, CINC, IL10 and TGF- $\beta 1$ was determined by Kruskal-Wallis tests, followed by Dunn's multiple comparison post-test. The data from the microtomographic and histometric analyses were assessed by analysis of variance (ANOVA) followed by post-hoc Tukey test. Two- 
tailed t-test was performed to evaluate the microbiologic data. The significance level was set at $5 \%$ in all tests.

\section{Results}

\section{Micro-CT analyses}

Group EP-SRP-PROB presented greater BV and reduced BP and ABL when compared with Group EP-SRP (ANOVA, $p<0.05$ ). Means and standard deviations of $\mathrm{ABL}, \mathrm{BV}$ and $\mathrm{BP}$, as well as intergroup comparisons, are depicted in Table 1.

Table 1. Micro-CT analyses. Means and standard deviations (SD) of BV (\%), BP (\%) and ABL $(\mu \mathrm{m})$ of Groups C, PROB, EP-SRP and EP-SRP-PROB, with comparisons among groups.

\begin{tabular}{|c|c|c|c|c|}
\hline \multirow[t]{4}{*}{ VARIABLE } & \multicolumn{4}{|c|}{ EXPERIMENTAL GROUPS } \\
\hline & $\mathbf{C}$ & PROB & EP-SRP & EP-SRP-PROB \\
\hline & $\mathrm{N}=8$ & $\mathrm{~N}=8$ & $\mathrm{~N}=8$ & $\mathrm{~N}=8$ \\
\hline & Mean $\pm \mathrm{SD}$ & Mean \pm SD & Mean \pm SD & Mean \pm SD \\
\hline BV $(\%)$ & $80.3 \pm 9.3^{*}$ & $83.9 \pm 2.5^{*}$ & $31.8 \pm 14.1$ & $67.1 \pm 20.9^{*}$ \\
\hline BP $(\%)$ & $19.3 \pm 9.3^{*}$ & $17.1 \pm 2.9^{*}$ & $70.5 \pm 16.9$ & $22.8 \pm 17.8^{*}$ \\
\hline $\mathrm{ABL}(\boldsymbol{\mu m})$ & $1537 \pm 331.8^{*}$ & $1754 \pm 610.9^{*}$ & $4682 \pm 1634$ & $2853 \pm 820.6^{*}$ \\
\hline
\end{tabular}

*Significant difference when compared with Group EP-SRP $(p<0.05)$

$\mathrm{BV}=$ bone volume $\mathrm{BP}=$ bone porosity $; \mathrm{ABL}=$ alveolar bone level.

\section{Histomorphometric analysis of periodontal tissues}


Groups with EP showed greater alveolar bone resorption and AL than Groups C and PROB $(p<0.05$; Figs 1A and 1B), which did not present AL. When compared with Group EP-SRP, Group EP-SRP-PROB presented ANB and AL significantly reduced $(p<0.05$; Fig $1 \mathrm{~A}$ and 1B).

In Groups $\mathrm{C}$ and $\mathrm{PROB}$, periodontal ligament (PL) presented a great amount of collagen fibers, fibroblasts and blood vessels. Collagen fibers were inserted both in cementum and in alveolar bone. The bone tissue of the furcation region presented a few irregularities on its surface (Figs 1C and 1D). In both groups, junctional and sulcular epithelia integrities were observed in the interproximal area (Figs $1 \mathrm{G}$ and $1 \mathrm{H}$ ).

In Group EP-SRP, connective tissue presented moderate inflammatory infiltrate consisting primarily of neutrophils in the furcation region. The bone of the interradicular septum showed irregular outer contours (Fig 1E) due to the presence of numerous active osteoclasts. A severe damage of the junctional and sulcular epithelia was observed in the interproximal area (Fig 1I).

In Group EP-SRP-PROB, the inflammatory infiltrate in the furcation region was mainly composed of neutrophils and was less extensive than the one observed in Group EP-SRP. Bone tissue in the interradicular septum presented irregular external contour and was covered with osteoblasts or bone lining cells. Few active osteoclasts were observed. Bone neoformation within the interradicular septum was observed in the majority of the specimens (Fig 1F). The junctional and sulcular epithelia of the interproximal area were less injured than that of Group EP-SRP (Fig 1J).

Fig 1. Histomorphometric analysis of periodontal tissues. Means and standard deviations of ANB (A; furcation area) and $\mathrm{AL}$ (B; interproximal area), with comparisons among groups. Photomicrographs of periodontal tissues in the furcation 
(C-F) and interproximal areas (G-J) of mandibular first molars: Group C (C and G); Group PROB (D and H); Group EP-SRP (E and I); Group EP-SRP-PROB (F and J). Abbreviations and symbols: $\mathrm{ab}=$ alveolar bone; $\mathrm{ct}=$ connective tissue; pdl $=$ periodontal ligament; $\mathrm{ANB}=$ area of no bone; $\mathrm{AL}=$ attachment loss $; \mathrm{FM}=$ first molar; $\mathrm{SM}=$ second molar; black arrows = cementoenamel junction; white arrows = epithelial attachment; $*=p<0.05 ; * *=p<0.01 ; * * *=p<0.001$. Scale bars: C-J $=200 \mu \mathrm{m}$. (Hematoxylin and Eosin stain).

\section{Immunohistochemical analyses of periodontal tissues}

The number of TRAP-positive multinucleated cells was greater in Groups EP when compared with Groups C and PROB ( $p<0.05$; Fig 2). Group EP-SRP-PROB presented less TRAP-positive multinucleated osteoclasts than Group EP-SRP $(p<0.05$; Fig 2).

Fig 2. Immunohistochemical analyses - TRAP. Means and standard deviations of the number of TRAP-positive multinucleated cells (A), with comparisons among groups. Photomicrographs showing immunolabeling for TRAP (B-E) in the furcation areas of mandibular first molars: Group C (B); Group PROB (C); Group EP-SRP (D); Group EP-SRP-PROB (E). Abbreviations and symbols: $a b=$ alveolar bone; $\mathrm{ct}=$ connective tissue; pdl = periodontal ligament; black arrowhead = TRAP-positive multinucleated cell; $*=p<0.05 ; * *=p<0.01 ; * * *=p<0.001$. Scale bars: B-E $=20 \mu \mathrm{m}$. (Hematoxylin counterstaining).

Group EP-SRP-PROB presented lower immunolabeling patterns for IL-1 $\beta$ and CINC (Fig 3) and higher immunolabeling patterns for TGF- $\beta 1$ and IL-10 (Fig 4) than Group EP-SRP $(p<0.05)$. 
Fig 3. Immunohistochemical analyses - IL-1ß and CINC. Medians, interquartile range and maximum and minimum values of the immunolabeling scores for IL-1 $\beta$ (A) and CINC (B), with comparisons among groups. Photomicrographs showing immunolabeling for IL-1 $\beta$ (C-F) and CINC (G-J) in the furcation areas of mandibular first molars: Group C (C and G); Group PROB (D and H); Group EP-SRP (E and I); Group EP-SRP-PROB (F and J). Abbreviations: $a b=$ alveolar bone; $\mathrm{ct}=$ connective tissue; $\mathrm{pdl}=$ periodontal ligament ${ }^{*}=p<0.05$. Scale bars: C-J $=80 \mu \mathrm{m}$. (Hematoxylin counterstaining).

Fig 4. Immunohistochemical analyses - IL-10 and TGF- $\beta 1$. Medians, interquartile range and maximum and minimum values of the immunolabeling scores for IL-10 (A) and TGF- $\beta 1$ (B), with comparisons among groups. Photomicrographs showing immunolabeling for IL-10 (C-F) and TGF- $\beta 1(\mathrm{G}-\mathrm{J})$ in the furcation areas of mandibular first molars: Group C (C and G); Group PROB (D and H); Group EP-SRP (E and I); Group EP-SRP-PROB (F and J). Abbreviations: $a b=$ alveolar bone; $\mathrm{ct}=$ connective tissue; pdl $=$ periodontal ligament ${ }^{*}=p<0.05$. Scale bars: C-J $=80 \mu \mathrm{m}$. (Hematoxylin counterstaining).

\section{Histomorphometric analysis of small intestine}

Group PROB presented greater $\mathrm{VH}$ and $\mathrm{CD}$ in duodenum, jejunum and ileum samples than the other groups ( $p<0.05$, Figs 5A and 5B). Group EP-SRP demonstrated VH greater than Group $C$ in ileum samples ( $p<0.05$, Fig. 51). Group EP-SRP-PROB presented greater CD in duodenum and jejunum samples than Group EP-SRP $(p<0.05$, Fig. 5B).

A normal intestinal structure was observed in all groups, characterized by a mucosal layer presenting villosities covered with simple cylindrical epithelium, 
calciform cells and crypt of Lieberkühn. In groups PROB, the crypt of Lieberkühn and villosities were developed and presented a greater number of calciform cells when compared with the other groups in duodenum (Figs 5C-5F), jejunum and ileum samples.

Fig 5. Histomorphometric analysis of small intestine. Mean values and standard deviations of $\mathrm{VH}(\mathrm{A})$ and $\mathrm{CD}$ (B) in intestinal sections, with comparisons among groups. Photomicrographs of small intestine (duodenum sections): Group C (C); Group EP-SRP (D); Group PROB (E); Group EP-SRP-PROB (F). Abbreviations and symbols: $\mathrm{LC}=$ crypt of Lieberkühn; $\mathrm{VH}=$ villous height $\mathrm{CD}=$ crypt depth; black arrowhead = calciform cells; $*=$ Significant difference $(p<0.05)$ when compared with Groups C, EPSRP and EP-SRP-PROB; ${ }^{\dagger}=$ Significant difference $(p<0.05)$ between Groups EP-SRP and EP-SRP-PROB; ${ }^{\ddagger}=$ Significant difference $(p<0.05)$ between Groups C and EPSRP-PROB; ${ }^{\S}=$ Significant difference $(p<0.05)$ between Groups C and EP-SRP. Scale bars: $\mathrm{C}-\mathrm{F}=50 \mu \mathrm{m}$. (Hematoxylin and Eosin stain).

\section{Effects of B. lactis HN019 on ligature-associated microbiota}

The ratio between aerobic and anaerobic bacteria was higher in Group Test when compared with Group Placebo $(p<0.05)$. Means and standard deviations of the ratio are reported in the Fig 6.

Fig 6. Effects of $B$. lactis HN019 on ligature-associated microbiota. Means and standard deviations of the ratios between aerobic and anaerobic bacteria in groups Test and Placebo. ${ }^{*}=$ Significant difference $(p<0.05)$ when compared with Group Placebo. 


\section{Discussion}

The possibility to manage oral diseases with a natural, non-invasive and nonstressful method is particularly appealing, and may prevent problems related to pharmacological treatments, such as the use of antibiotics [21]. In this study, the probiotic therapy enhanced the effects of SRP in periodontitis treatment in rats. It influenced the balance of pro-inflammatory (IL-1 $\beta$ and CINC) and anti-inflammatory (IL-10 and TGF- $\beta 1$ ) cytokines and reduced the number of osteoclasts, the loss of attachment and alveolar bone, the local inflammation as well as favored the tissue repair.

To the authors' knowledge, this is the first study to administrate the genus Bifidobacterium as an adjunct to SRP in periodontitis. The use of this selected strain was supported by an in vitro study [22]. These authors showed that bifidobacteria could survive in saliva and bind to Fusobacterium nucleatum-covered hydroxyapatite. This finding may be a critical step for a successful periodontal therapy, since this coaggregation may decrease the number of periodontopathogens in oral biofilm. In fact, the most important function of Fusobacterium nucleatum in subgingival bacterial biomass appears to be its capacity to facilitate the co-aggregation of other periodontal pathogens, such as Aggregatibacter actinomycetemcomitans, Porphyromonas gingivalis and Tannerella forsythia [23]. In the present study, the subgingival biofilm of the animals non-ligated (Groups C and PROB) or treated with SRP (Groups EP-SRP and EP-SRP-PROB) were not evaluated due to the inherent limitations of the experimental model. Without the presence of ligatures in Wistar rats, it is difficult to collect an adequate amount of oral biofilm for appropriate microbiologic analyses. Therefore, a parallel experiment was conducted to evaluate the effects of B. lactis HN019 on the microbiota associated with the ligature during the development of EP in rats. It was 
observed that this probiotic agent modulated the oral microbiota in a way that favored the growth of aerobic bacteria at the expense of anaerobic bacteria. As periodontitisassociated bacteria are predominantly anaerobic [24], this finding suggests that $B$. lactis HN019 treatment may inhibit periodontitis, at least in part, through modulation of the periodontal microbiota. In fact, the animals treated with B. lactis HN019 in this parallel experiment presented less alveolar bone resorption in morphometric analysis (data shown in S1 Fig).

In this study, a lower expression of IL-1 $\beta$ and a greater expression of IL-10 were observed in Group EP-SRP-PROB when compared with Group EP-SRP. Higher levels of IL-10 were also observed in colon of gnotobiotic mice challenged with Salmonella typhimurium and treated with $B$. lactis [25]. IL-10 exerts inhibitory effects on IL-1 $\beta$ and tumor necrosis factor- $\alpha$, which present synergistic actions on inflammatory processes, amplifying the host response [26]. The elevated ratio IL-1 $\beta /$ IL-10 in gingival crevicular fluid may be related to progression of aggressive periodontitis [27].

The probiotic therapy as an adjunct to SRP also reduced the magnitude of the inflammatory response and improved tissue repair in Group EP-SRP-PROB, increasing the expression of TGF- $\beta 1$ in periodontal tissues. Previous studies have already demonstrated that $B$. lactis HN019 can increase TGF- $\beta 1$ levels in breast milk [28] and in blood [29]. TGF- $\beta$ suppresses collagenase production by fibroblasts and macrophages, enhances the expression of tissue inhibitors of matrix-metalloproteinases (MMPs), increases the synthesis of extracellular matrix molecules and promotes chemoattractant effects on bone cells [30].

A decreased number of TRAP-positive multinucleated cells was found in Group EP-SRP-PROB when compared with Group EP-SRP. This may be explained in part by the reduced expression of CINC (homolog of the human IL-8) in periodontal tissues of the animals treated with probiotic. Liu et al. (2010) [31] demonstrated that B. lactis 
HN019 exerts anti-inflammatory effects on the epithelium by down-regulating the secretion of IL-8. IL-8 has been implicated in a wide variety of diseases and is an important pro-inflammatory cytokine and immunomodulatory factor, which can induce osteoclast differentiation/maturation and the maintenance of bone-resorption activity involved in periodontal tissue destruction [32].

Group PROB presented greater CD and VH in duodenum, jejunum and ileum samples when compared with the other groups. Also, Group EP-SRP-PROB showed greater CD than Group EP-SRP in duodenum and jejunum samples. In fact, probiotics can improve the host mucosal barrier function leading to diminished immunologic reactivity, displacing deleterious microbes from the mucosal surface and modulating the mucosal immune system [33]. In a previous study of this group [18], it was demonstrated that probiotic supplementation protected the small intestine from reactive changes induced by EP. It is important to punctuate that a diminished intestinal inflammation might be related to an improved periodontal health. Grossner-Schreiber et al. (2006) [34] reported an increased prevalence of periodontal disease in patients with inflammatory bowel disease.

The present study provided a proof-of-concept that the probiotic B. lactis HN019 presents therapeutic potential in periodontitis treatment. Nevertheless, it was not possible to determine whether the effects of this probiotic strain on periodontitis occurred mainly because of antimicrobial or immunomodulatory properties. The findings of the present study need to be confirmed with more advanced experimental models in the phylogenetic scale and in clinical trials. It is also mandatory to analyze the influence of the vehicle by which this probiotic strain is administered in its therapeutic potential and oral colonization as well as its survival in the oral cavity. Besides, more studies are required to evaluate other modes of application and different therapeutic regimens. 


\section{Conclusion}

It can be concluded that the oral administration of $B$. lactis HN019 potentiates the effects of SRP in the treatment of EP in rats.

\section{Acknowledgements}

The authors thank Sao Paulo Research Foundation (FAPESP - scholarship to GCT and JPP). The authors also thank Marina Del Arco (Laboratory Assistant, Department Clinical Analyses, School of Pharmaceutical Sciences of Ribeirao Preto, University of São Paulo - USP, RibeirãoPreto / SP, Brazil) for technical support during the microbiological procedures.

\section{References}

1. Maekawa T, Hajishengallis G. Topical treatment with probiotic Lactobacillus brevis $\mathrm{CD} 2$ inhibits experimental periodontal inflammation and bone loss. J Periodontal Res. 2014;49(6): 785-791.

2. Teughels W, Durukan A, Ozcelik O, Pauwels M, Quirynen M, Haytac MC. Clinical and microbiological effects of Lactobacillus reuteri probiotics in the treatment of chronic periodontitis: a randomized placebo-controlled study. J Clin Periodontol. 2013;40(11): 1025-1035.

3. Araya M, Morelli L, Reid G, Sanders ME, Stanton C. Joint FAO/WHO Working Group Report on Drafting Guidelines for the Evaluation of Probiotics in Food. 2002. Available from: www.who.int/entity/foodsafety/fs_management/en/probiotic_guidelines.pdf. 
4. Hemarajata P, Versalovic J. Effects of probiotics on gut microbiota: mechanisms of intestinal immunomodulation and neuromodulation. Therap Adv Gastroenterol. 2013;6(1): 39-51.

5. Vivekananda MR, Vandana KL, Bhat KG. Effect of the probiotic Lactobacilli reuteri (Prodentis) in the management of periodontal disease: a preliminary randomized clinical trial. $\mathbf{J}$ Oral Microbiol. 2010; 2;2. doi: 10.3402/jom.v2i0.5344

6. Shah MP, Gujjari SK, Chandrasekhar VS. Evaluation of the effect of probiotic (Inersan®) alone, combination of probiotic with doxycycline and doxycycline alone on aggressive periodontitis - a clinical and microbiological study. J Clin Diagn Res. 2013;7(3): 595-600.

7. Ince G, Gursoy H, Ipci SD, Cakar G, Emekli-Alturfan E, Yilmaz S. Clinical and biochemical evaluation of lozenges containing Lactobacillus reuteri as an adjunct to non-Surgical periodontal therapy in chronic periodontitis. J Periodontol. 2015;86(6): 746-754.

8. Tekce M, Ince G, Gursoy H, Dirikan Ipci S, Cakar G, Kadir T, et al. Clinical and microbiological effects of probiotic lozenges in the treatment of chronic periodontitis: a 1-year follow-up study. J Clin Periodontol. 2015;42(4): 363-372.

9. Teughels W, Loozen G, Quirynen M. Do probiotics offer opportunities to manipulate the periodontal oral microbiota? J Clin Periodontol. 2011; 38(Suppl 11): 159S-177S.

10. Prasad J, Smart JB, Gopal PK, Gill HS. Selection and characterisation of Lactobacillus and Bifidobacterium strains for use as probiotics. International Dairy Journal. 1998;8(12): 993-1002.

11. Biavati B, Vescovo M, Torriani S, Bottazzi V. Bifidobacteria: history, ecology, physiology and applications. Ann Microbiol. 2000;50: 117-131. 
12. Gill HS, Rutherfurd KJ, Prasad J, Gopal PK. Enhancement of natural and acquired immunity by Lactobacillus rhamnosus (HN001), Lactobacillus acidophilus (HN017) and Bifidobacterium lactis (HN019). Br J Nutr. 2000; 83(2): 167-76.

13. Caglar E, Kuscu OO, Selvi Kuvvetli S, Kavaloglu Cildir S, Sandalli N, Twetman S. Short-term effect of ice-cream containing Bifidobacterium lactis $\mathrm{Bb}-12$ on the number of salivary mutans streptococci and lactobacilli. Acta Odontol Scand. 2008;66(3): 154-158.

14. Singh RP, Damle SG, Chawla A. Salivary mutans streptococci and lactobacilli modulations in young children on consumption of probiotic ice-cream containing Bifidobacterium lactis Bb12 and Lactobacillus acidophilus La5. Acta Odontol Scand. 2011;69(6): 389-394.

15. Toiviainen A, Jalasvuori H, Lahti E, Gursoy U, Salminen S, Fontana M, et al. Impact of orally administered lozenges with Lactobacillus rhamnosus GG and Bifidobacterium animalis subsp. lactis BB-12 on the number of salivary mutans streptococci, amount of plaque, gingival inflammation and the oral microbiome in healthy adults. Clin Oral Investig. 2015;19(1): 77-83.

16. Hoffman FA, Heimbach JT, Sanders ME, Hibberd PL. Executive summary: scientific and regulatory challenges of development of probiotics as foods and drugs. Clin Infect Dis. 2008;1;46(Suppl 2): 53S-57S.

17. Oliveira LFF, Salvador SL, Silva PHF, Furlaneto FAC, Figueiredo L, Casarin R, et al. Benefits of Bifidobacterium animalis subsp lactis probiotic in experimental periodontitis. J Periodontol. 2016;23: 1-20 [Epub ahead of print].

18. Messora MR, Oliveira LF, Foureaux RC, Taba M Jr, Zangeronimo MG, Furlaneto FA, et al. Probiotic therapy reduces periodontal tissue destruction and 
improves the intestinal morphology in rats with ligature-induced periodontitis. J Periodontol. 2013;84(12): 1818-1826.

19. Lisboa MR, Gondim DV, Ervolino E, Vale ML, Frota NP, Nunes NL, et al. Effects of electroacupuncture on experimental periodontitis in rats. $\mathrm{J}$ Periodontol. 2015;86(6): 801-811.

20. Furlaneto FA, Nunes NL, Oliveira Filho IL, Frota NP, Yamamoto KO, Lisboa MR, et al. Effects of locally administered tiludronic acid on experimental periodontitis in rats. J Periodontol. 2014;85(9): 1291-1301.

21. Nissen L, Sgorbati B, Biavati B, Belibasakis GN. Lactobacillus salivarius and L. gasseri down-regulate Aggregatibacter actinomycetemcomitans exotoxins expression. Ann Microbiol. 2014;64: 611-617.

22. Haukioja A, Yli-Knuuttila H, Loimaranta V, Kari K, Ouwehand AC, Meurman JH, et al. Oral adhesion and survival of probiotic and other lactobacilli and bifidobacteria in vitro. Oral Microbiol Immunol. 2006;21(5): $326-332$.

23. Periasamy S, Kolenbrander PE. Mutualistic biofilm communities develop with Porphyromonas gingivalis and initial, early, and late colonizers of enamel. J Bacteriol. 2009;191(22): 6804-6811.

24. Darveau RP. Periodontitis: a polymicrobial disruption of host homeostasis. Nat Rev Microbiol. 2010;8(7): 481-490.

25. Martins AK, Martins FS, Gomes DA, Elian SD, Vieira AT, Teixeira MM, et al. Evaluation of in vitro antagonism and of in vivo immune modulation and protection against pathogenic experimental challenge of two probiotic strains of Bifidobacterium animalis var. lactis. Arch Microbiol. 2010;192(12): 995-1003.

26. Moore KW, de Waal Malefyt R, Coffman RL, O'Garra A. Interleukin-10 and the interleukin-10 receptor. Annu Rev Immunol. 2001;19: 683-765. 
27. Teles RP, Gursky LC, Faveri M, Rosa EA, Teles FR, Feres M, et al. Relationships between subgingival microbiota and GCF biomarkers in generalized aggressive periodontitis. J Clin Periodontol. 2010;37(4): 313-323.

28. Prescott SL, Wickens K, Westcott L, Jung W, Currie H, Black PN, et al. Supplementation with Lactobacillus rhamnosus or Bifidobacterium lactis probiotics in pregnancy increases cord blood interferon-gamma and breast milk transforming growth factor-beta and immunoglobin A detection. Clin Exp Allergy. 2008;38(10): 1606-1614.

29. Ouwehand AC, Bergsma N, Parhiala R, Lahtinen S, Gueimonde M, FinneSoveri $\mathrm{H}$, et al. Bifidobacterium microbiota and parameters of immune function in elderly subjects. FEMS Immunol Med Microbiol. 2008;53(1): 18-25.

30. Dereka XE, Markopoulou CE, Vrotsos IA. Role of growth factors on periodontal repair. Growth Factors. 2006;24(4): 260-267.

31. Liu C, Zhang ZY, Dong K, Guo XK. Adhesion and immunomodulatory effects of Bifidobacterium lactis HN019 on intestinal epithelial cells INT-407. World J Gastroenterol. 2010;14;16(18): 2283-2290.

32. Zhang Y, Li X. Lipopolysaccharide-regulated production of bone sialoprotein and interleukin- 8 in human periodontal ligament fibroblasts: the role of toll-like receptors 2 and 4 and the MAPK pathway. J Periodontal Res. 2015;50(2): 141151.

33. Vanderpool C, Yan F, Polk DB. Mechanisms of probiotic action: Implications for therapeutic applications in inflammatory bowel diseases. Inflamm Bowel Dis. $2008 ; 14(11)$ : $1585-1596$.

34. Grossner-Schreiber B, Fetter T, Hedderich J, Kocher T, Schreiber S, Jepsen S. Prevalence of dental caries and periodontal disease in patients with 
inflammatory bowel disease: a case-control study. J Clin Periodontol. 2006;33(7): 478-484.

\section{Supporting information}

S1 Fig. Morphometric analysis. (A) Means and standard deviations of the Area (mm2) of No Bone (delimited in the lingual region of mandibular first molars between the cemento-enamel junction and alveolar bone crest) of Groups Placebo and Test, with comparisons between groups. * = Significant difference (Test $\mathrm{t}, p<0.05)$ when compared with Group Placebo. $(\mathrm{B}, \mathrm{C})$ Representative images of the specimens of the animals, stained with methylene blue in order to evidence the cemento-enamel junction and the bone crest. (B) Group Placebo; (C) Group Test. 
Figure 1
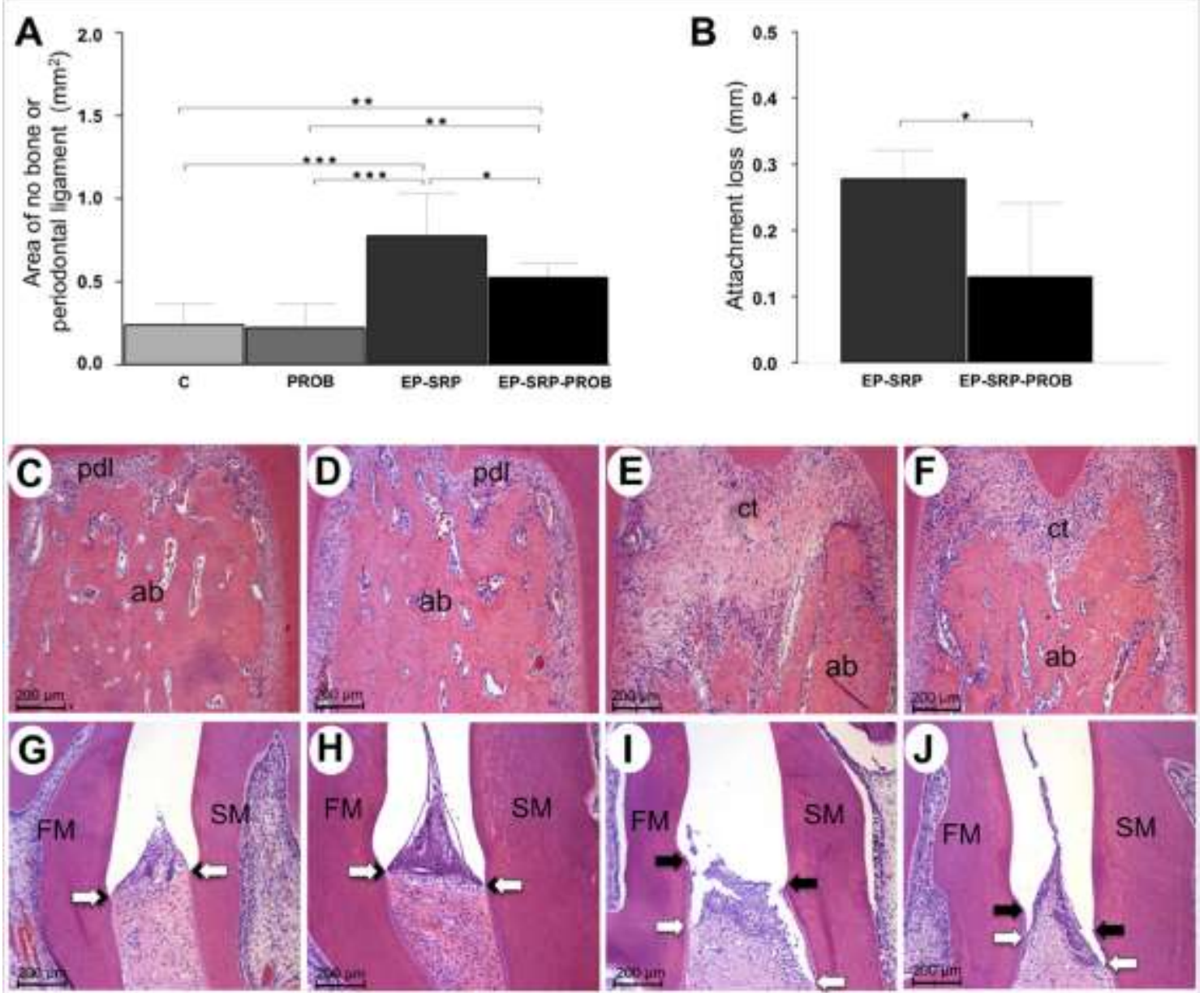
Figure 2

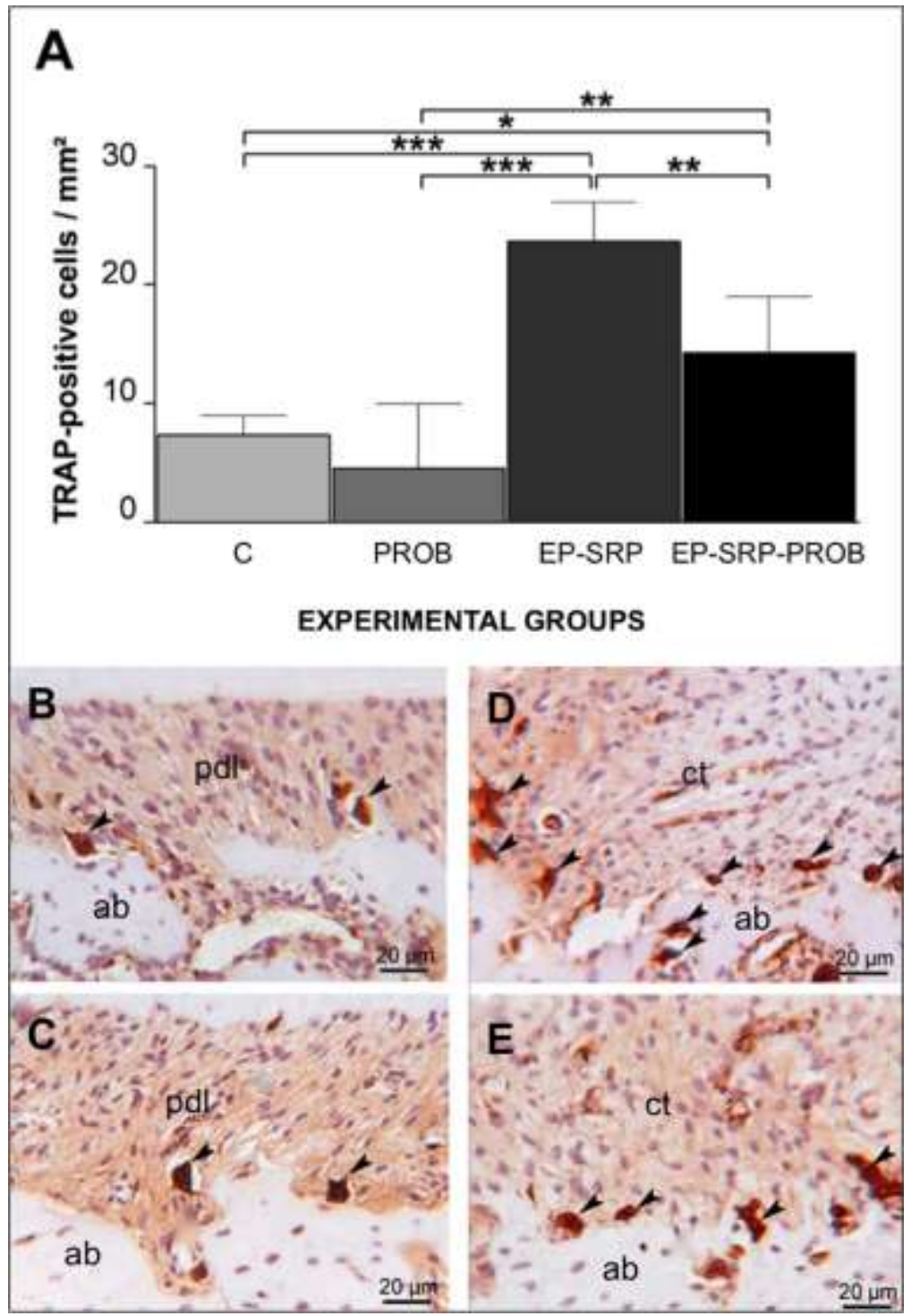


Figure 3

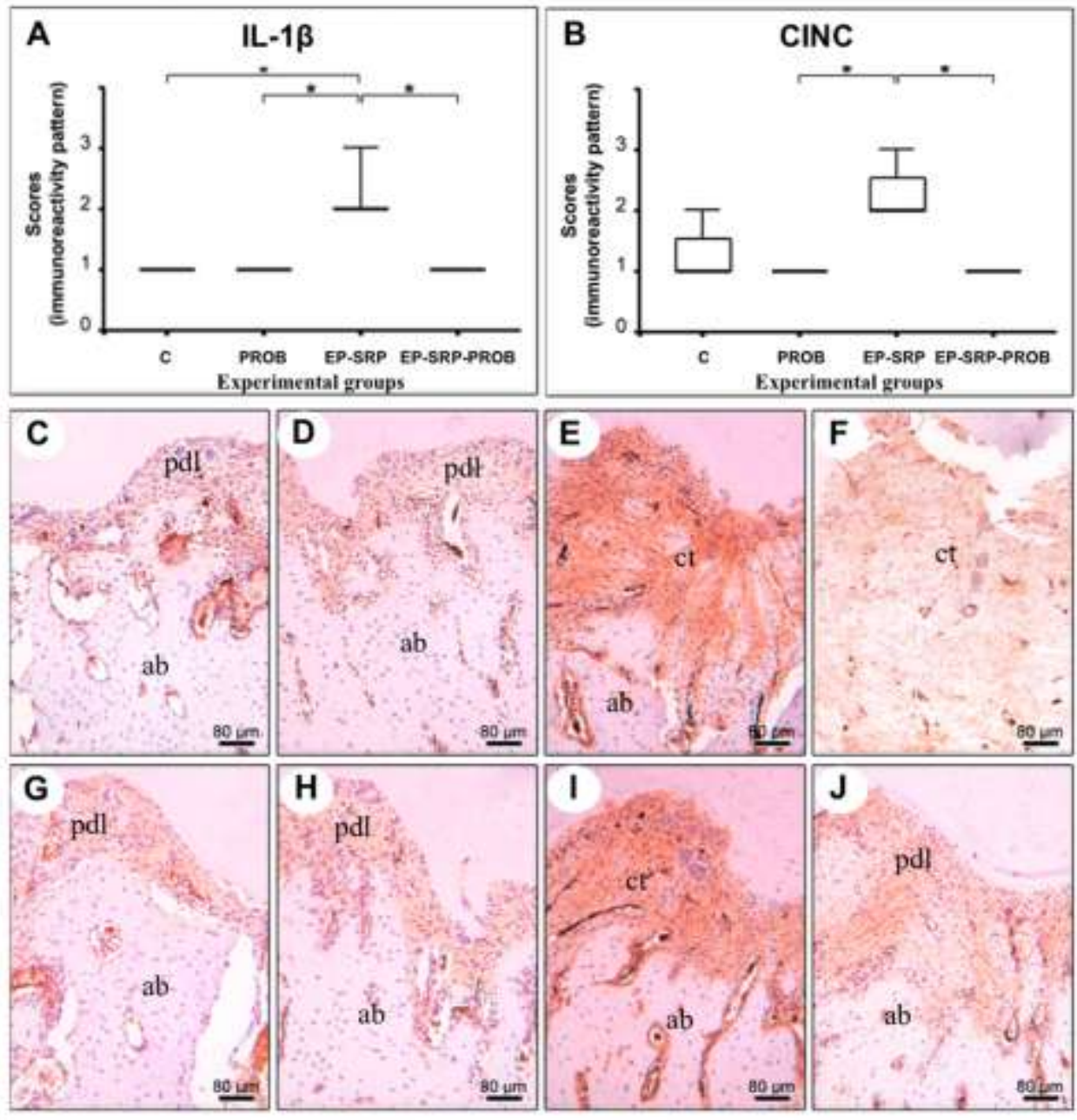


Figure 4

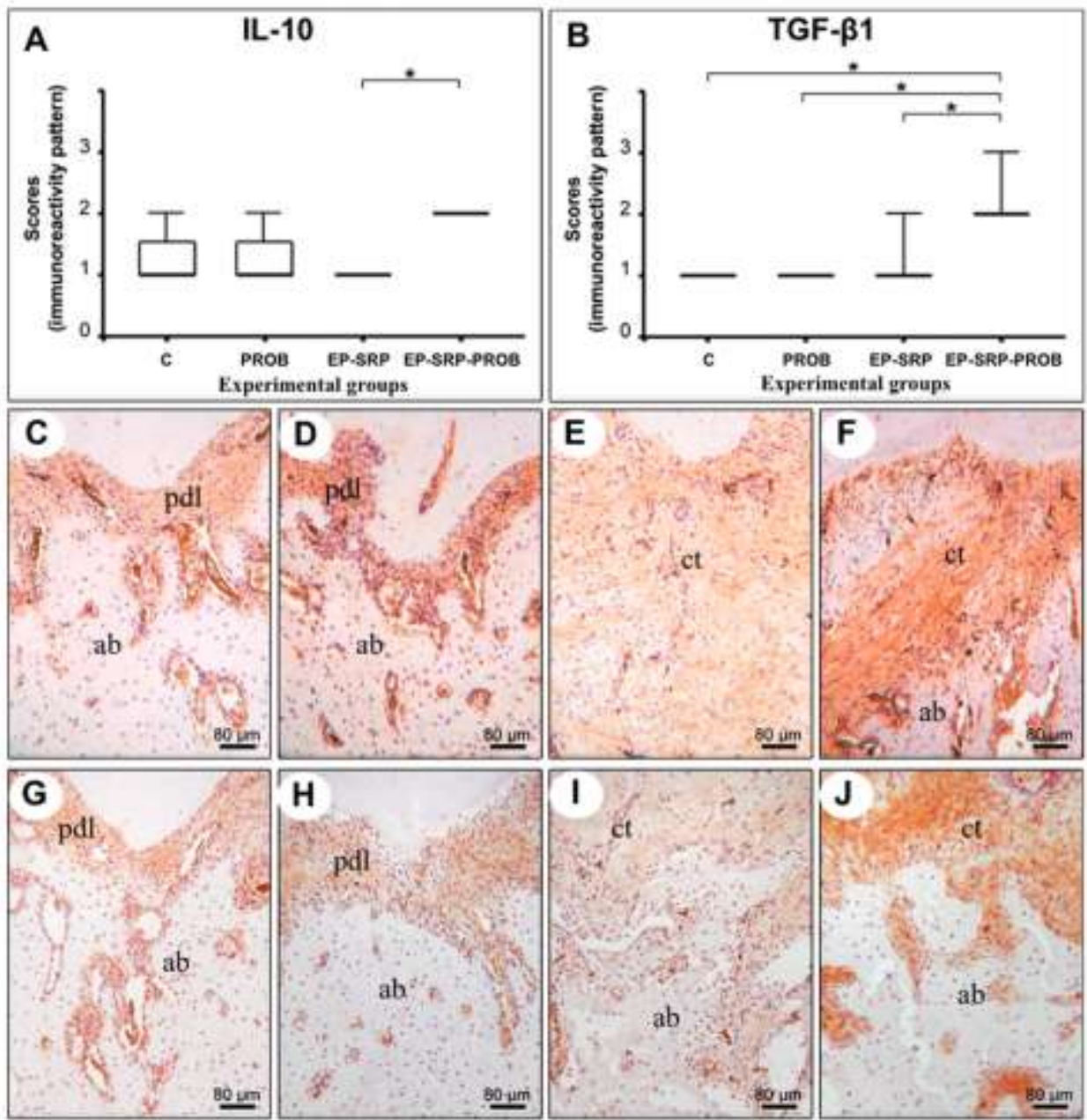


Figure 5
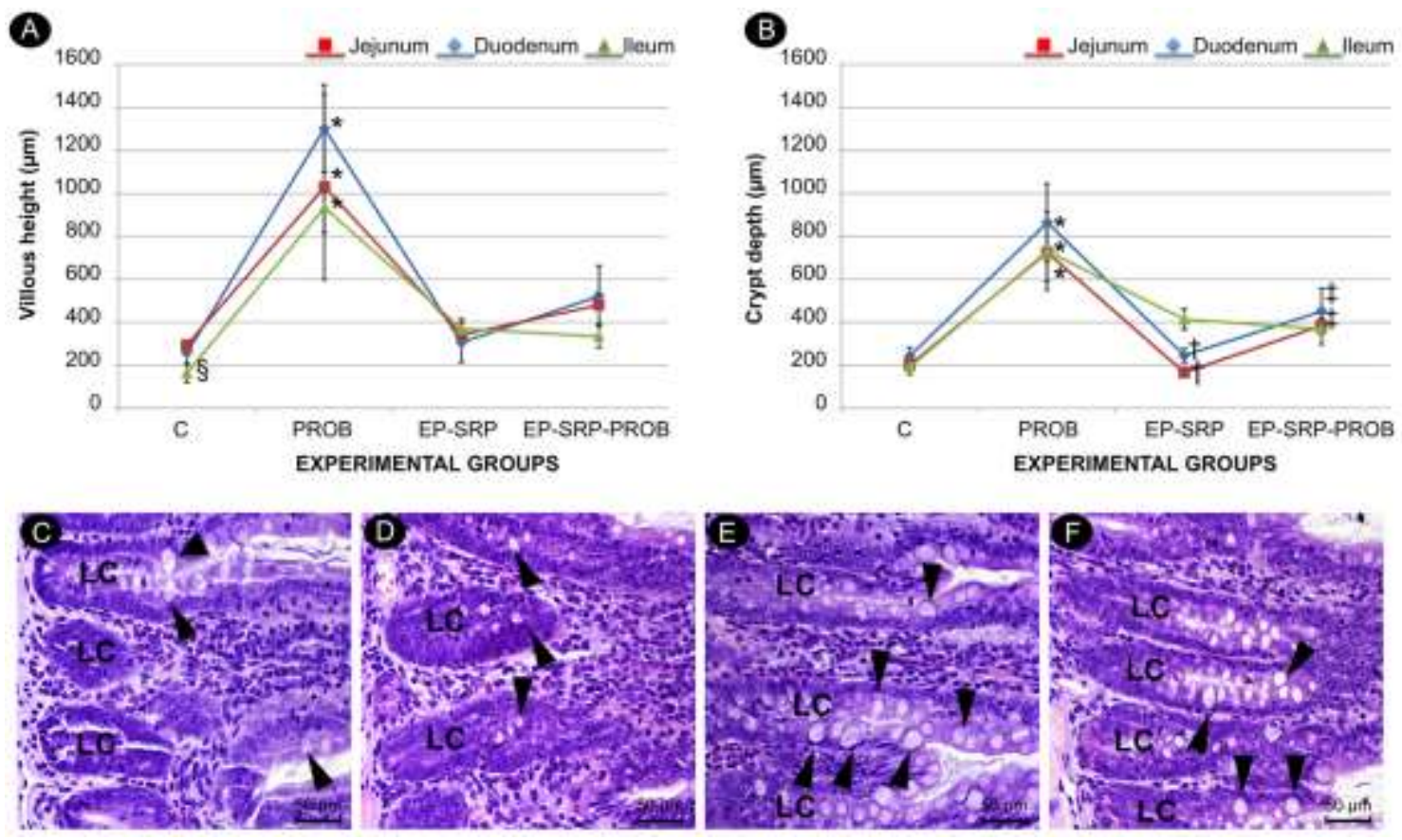
S1

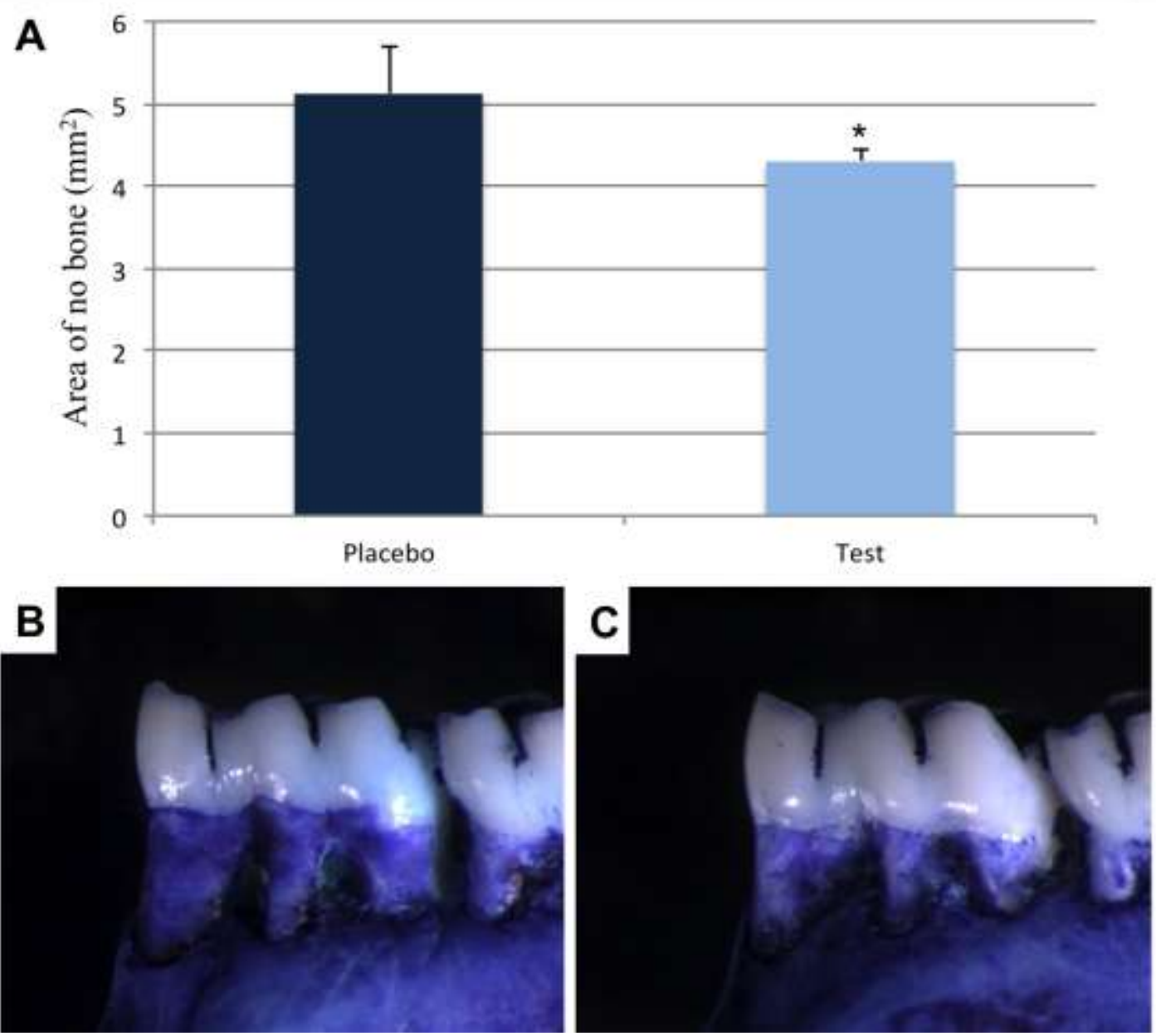

